\title{
Nova espécie de Phalotris, redescrição de $P$. tricolor e osteologia craniana (Serpentes, Elapomorphinae)
}

\author{
Thales de Lema ${ }^{1}$, Fernanda Maurer D’Agostini ${ }^{1,2}$ \& Lize Helena Cappellari ${ }^{1,2}$
}

1. Laboratório de Herpetologia, Faculdade de Biociências e Museu de Ciências e Tecnologia, Pontifícia Universidade Católica do Rio
Grande do Sul, Caixa Postal 1429, 90619-900 Porto Alegre, RS, Brasil. (crothales@ pucrs.br) Grande do Sul, Caixa Postal 1429, 90619-900 Porto Alegre, RS, Brasil.
2. Bolsista de Doutorado CAPES. (dagostin@ pucrs.br, lize@ pucrs.br)

\begin{abstract}
Description of new species of Phalotris, redescription of $P$. tricolor and skull osteology (Serpentes, Elapomorphinae). The comparison of the types of Phalotris tricolor (Duméril, Bibron \& Duméril, 1854) and Elapomorphus punctatus Lema, 1979 showed that both names refer to a single species; up to date the current name $P$. tricolor is a compound of $P$. tricolor and an unknown species that is described here as P. matogrossensis sp. nov. from southwestern Brazil to adjacent Paraguay at Cerrado domain. The new species differs from $P$. tricolor mainly by white lower side of head, instead entirely black; white collar longer than the black collar, instead short with very longer black collar; black collar only dorsal, instead attaining ventral side; back ground coloration uniformly brilliant red, instead yellowish to brownish red, with widespread black dots usually in longitudinal series. The skull and hemipenis from both species do not present major differences. These species, plus P. mertensi (Hoge, 1955) and P. cuyanus (Cei, 1984), compose the tricolor group; a key is provided to identification of species.
\end{abstract}

KEYWORDS. New species, Phalotris tricolor, P. punctatus, distribution, taxonomy.

RESUMO. A comparação dos espécimes-tipo de Phalotris tricolor (Duméril, Bibron \& Duméril, 1854) e Elapomorphus punctatus Lema, 1979 demonstrou que ambos nomes se referem ao mesmo táxon; o nome P. tricolor, empregado até o momento, é um complexo de $P$. tricolor e uma espécie ainda não conhecida, descrita aqui como $P$. matogrossensis sp. nov. distribuída do sudoeste do Brasil às áreas adjacentes no Paraguai, em formações de Cerrado. A nova espécie difere de P. tricolor principalmente por apresentar região inferior da cabeça branca, ao invés de inteiramente preta; colar branco mais longo que o preto; ao invés de curto e com um colar preto muito mais longo; colar preto apenas dorsal, ao invés de atingir os lados do ventre; coloração dorsal de fundo vermelha brilhante e não amarelada ou marrom-avermelhada, com pontos pretos dispersos em séries longitudinais. O crânio e hemipênis das duas espécies não apresentam maiores diferenças. As duas espécies, mais P. mertensi (Hoge, 1955) e P. cuyanus (Cei, 1984), compõem o grupo tricolor e é apresentada uma chave para a identificação das espécies do grupo.

PALAVRAS-CHAVE. Espécie nova, Phalotris tricolor, P. punctatus, distribuição, taxonomia.

Phalotris tricolor foi descrita por DumÉRIL et al. (1854) com base em exemplares da Bolívia; P. punctatus foi descrita por LEMA (1979) sobre espécimes da Argentina tombados em coleções daquele país, como P. tricolor. Até o momento, o nome P. tricolor vem sendo usado para exemplares procedentes do Brasil e para alguns da Bolívia, Paraguai e Argentina, enquanto que, P. punctatus, para espécimes da Argentina e Paraguai. GIRAUDO (2001), ao examinar exemplares do nordeste da Argentina, duvidou da validade das duas espécies. Estas espécies constituem o grupo tricolor (Ferrarezzi, 1993) que está constituído por P. cuyanus (Cei, 1984), P. mertensi (Hoge, 1955), P. punctatus (Lema, 1979) e P. tricolor (Duméril, Bibron \& Duméril, 1854) cuja diferenciação é apresentada ao final. A análise dos tipos e de séries de exemplares de $P$. tricolor e $P$. punctatus produziram subsídios para a proposição de um novo arranjo taxonômico que inclui a descrição de uma nova espécie e a inclusão de $P$. punctatus como sinônimo júnior de $P$. tricolor.

\section{MATERIAL E MÉTODOS}

Acrônimos segundo LEviton et al. (1985): ANSP, The Academy of Natural Sciences of Philadelphia (E.U.A.); CAS, California Academy of Sciences, San Francisco, California (E.U.A.); CENA, Coleção Avelino
Barrio, Instituto de Microbiología Gustav Malbrán (exCHINM), transferida para MACN, como coleção isolada, BA (Argentina); CHAF, coleção Arlindo Figueiredo Beda, Universidade Federal de Mato Grosso do Sul, campus Aquidauana (Brasil); CMNH, Carnegie Museum of Natural History, Pittsburgh (E. U. A.); FHCM, Facultad de Ciencias, Montevideo (Uruguai); FML, Fundación Miguel Lillo, Tucumán (Argentina); IB, Instituto Butantan, SP (Brasil); IPSP, Instituto Pinheiros Produtos Terapêuticos S.A. (fechado), SP (Brasil); MACN, Museo Argentino de Ciencias Naturales "Bernardino Rivadavia", Buenos Aires (Argentina); MCN, Museu de Ciências Naturais, Fundação Zoobotânica do Rio Grande do Sul, Porto Alegre, RS (Brasil); MCP, Museu de Ciências e Tecnologia, Pontifícia Universidade Católica do Rio Grande do Sul, Porto Alegre, RS (Brasil); MHNC, Museu de História Natural de Capão da Imbuia, Curitiba, PR (Brasil); MHNM, Museo Nacional de Historia Natural (fechado), Montevideo (Uruguai); MHNP, Museo Nacional de Historia Natural, Asunción (Paraguai); MLP, Museo de La Plata, La Plata (Argentina); MNHN, Muséum National d'Histoire Naturelle, Paris (França); MSNG, Museo de Storia Naturale de Genova (Itália); MZSP, Museu de Zoologia, Universidade de São Paulo, São Paulo, SP (Brasil); MZUT, Museo Regionale de Scienze Naturali de Torino (Itália); NMW, Naturhistorisches 
Museum zu Wien (Áustria); UNEC, Museo de la Universidad Nacional del Nordeste, Corrientes (Argentina); USNM, Museum of Natural History, Washington (E. U. A.); ZSM, Zoologisches Museum zu Berlin (Alemanha). Exemplares assinalados por asterisco não foram examinados.

O mapeamento das localidades foi feito com o programa Encarta Interative Atlas, da Microsoft Inc., edição de 2001, versão 9.00.00.07.02 de 1995-1999.

Abreviaturas usadas para folidose: CL, placa cloacal (anal); DO, escama dorsal; FR, placa frontal; GU, escama gular; IL, placa infralabial; IN, placa internasal; MA, placa mentoneana anterior; ME, placa mental; MM, placas mentoneanas; MP, placa mentoneana posterior; NA, placa nasal, OC, escama occipital; PA, placa parietal; PAV, zona paraventral; PF, placa prefrontal; PR, placa preocular; PS, placa postocular; PV, escama preventral; PVC, porção visível de cima da rostral; $\mathrm{RG}$, região gular; $\mathrm{RM}$, região mental; RO, placa rostral; SC, escama subcaudal; SIN, sutura entre IN; SL, placa supralabial; SO, placa supraocular; SP, escamas supracaudais; TA, placa temporal anterior; TE, placa terminal; TP, placa temporal posterior; TT, placas temporais; VE, escamas ventrais.

Abreviaturas para medidas: COCA, comprimento da cabeça; COCU, comprimento da cauda; COTO, comprimento total; COTR, comprimento do tronco; DBO, distância do olho ao bordo oral; DPF, distância do olho à ponta do focinho; HA, altura da cabeça no nível dos parietais; ha, altura da cabeça no nível das narinas; LA, maior largura da cabeça tomada no nível dos parietais; la, menor largura da cabeça tomada no nível das narinas; SVL, comprimento rostro-anal. Todas as medidas são apresentadas em milímetros e foram aferidas conforme LEMA \& ReNNER (1998). Medidas foram tomadas com calibrador digital, metro de pano ou de metal, e linha branca em exemplares de posição difícil de medir. Proporções usadas: $\mathrm{R}_{1}$, COTO/COCU; $\mathrm{R}_{2}$, COCU/COTO; $\mathrm{R}_{3}, \mathrm{COCA} / \mathrm{COTO} ; \mathrm{R}_{4}, \mathrm{SC} / \mathrm{VE}$.

A osteologia craniana foi apresentada sobre exemplares procedentes de três áreas fisionômicas diferentes: Monte, Chaco e Cerrado, respectivamente na Argentina, Paraguai e Brasil. A preparação dos hemipênis e dos crânios segue Lema \& DeIQUes (1995).

Elementos numéricos pares são separados por "barra" (direito/esquerdo), e.g.: OC $2 / 2$, dois pares de placas occipitais.

\section{Phalotris tricolor (Duméril, Bibron \& Duméril, 1854)}

$$
\text { (Figs. 1, 2; 3-7; 8-10; 22) }
$$

Elapomorphus tricolor DUMÉRIL, BIBRON \& DUMÉRIL, 1854:837 (localidade-tipo Santa Cruz de la Sierra, Santa Cruz, Bolívia, 17²47'S 6312"O); JAN, 1862:44; JAN \& SoRdELLI, 1865:14, est., fig. 2; STRAUCH, 1885:565; Boettger, 1891:91; Peracca, 1895:21; Boulenger, 1896:239, 242; SERIÉ, 1919:420; 1921:165; SCHOUTEN, 1931:14; SERIÉ, 1936:52, 59; Abalos et al, 1964:265, fig.19; Williams \& Francini, 1991:65 (parte).

Phalotris tricolor; COPE, 1861:302, 524; 1862:349; 1863:457; 1885:185

Elapomorphus punctatus LemA, 1979:837, figs.1-26 (localidade-tipo: Rosario de la Frontera, Salta, Argentina); CeI, 1986:412, fig. 75 (A, B); Williams \& Francini, 1991:64.

Elapomorphus (Phalotris) punctatus; LeMA, 1984:71, fig. 4; CEI, 1993:97, 557, fig. 86 (C, 4), est. 90 (1).
Phalotris punctatus; Ferrarezzi, 1993:23; Aquino et al., 1996:365; Leynaud \& Bucher, 1999:27; Giraudo, 2001:159, 166, fig. 30 , ests. $23-24$.

Tipos. Phalotris tricolor: o número de exemplarestipo é incerto (dois ou três) e a espécie foi descrita com base em mais de um exemplar sem a devida indicação. DuMÉRIL et al. (1854) afirmaram: "l'exemplaire fut apporté par D'Orbigny" (sic), como se fosse um exemplar, mas StRAUCh (1885) afirmou que eram dois os exemplares trazidos por D'Orbigny, ambos de Santa Cruz (Bolívia). Foram examinados por nós dois exemplares do MNHN como sendo tipos da espécie, contudo, um deles é um espécime de Clelia clelia (Daudin,1803), procedente da Venezuela, onde não existem serpentes Elapomorphinae. Deve ter ocorrido um equívoco por parte do curador que fez a remessa. JAN \& SoRDELLI (1865) ilustraram exemplar com anomalia de fusão das PS (1) em ambos os lados; também apresentaram outro com divisão das PR à direita (3 ao invés de 1). Sendo assim, ou o exemplar enviado não foi ilustrado, tendo sido perdido os espécimes figurados (três exemplares?), ou o desenhista errou ao ilustrar a folidose, possibilidade esta considerada improvável; não há indicação de que espécime foi extraído o crânio figurado (no exemplar examinado a cabeça está seca e compacta). Quando Duméril et al. (1854) registraram "o maior exemplar de todos", deixaram a dúvida se era $P$. tricolor ou os exemplares que examinaram de Elapomorphinae. Sendo o tipo examinado muito grande em relação ao tamanho geral de Elapomorphinae, a referência deve ser a esse exemplar que restou (MNHN 520) e que ora designamos lectótipo de $P$. tricolor por monotipia.

Diagnose. Espécie de grande porte que pode atingir quase um metro de comprimento. Difere de $P$. matogrossensis sp. nov. por apresentar cabeça preta no adulto com focinho pardo no jovem; colar branco de comprimento médio; colar preto longo, até 12 DO vertebrais que atingem as VE; margem posterior do colar preto irregular e sombreada posteriormente; cor de fundo dorsal castanho avermelhada a amarelada; geralmente apresenta pontos pretos espalhados no dorso tendendo à formação de estrias; alguns exemplares possuem manchas escuras paraventrais espaçadas irregularmente; corpo reforçado e mais curto; cor ventral geral amarelo citrino; média de VE 211,4; cauda mais longa (média de SC 35). P. matogrossensis sp. nov. apresenta cabeça preta com focinho vermelho; colar branco geralmente muito longo; colar preto com até $6 \mathrm{DO}$ vertebrais atingindo levemente a primeira fila de $\mathrm{VE}(?)$; margem posterior do colar preto pouco irregular e sem sombreado posterior; cor de fundo dorsal vermelho coral imaculada; região paraventral branco-imaculada; corpo muito alongado e isodiamétrico em toda sua extensão; cor ventral branca; média de VE 205; cauda mais curta (média de SC 26,6).

Difere de $P$. mertensi, por esta apresentar as escamas dorsais com ápice preto e a coloração de base dorsal vermelha brilhante, focinho avermelhado e colares branco e preto nuco-cervicais estreitos, sendo o preto mais estreito que o branco.

Difere de $P$. cuyanus, principalmente pela cor de fundo dorsal pardo-amarelada (ocre) imaculada desta última.

Redescrição do holótipo (MNHN 520). Pele com 


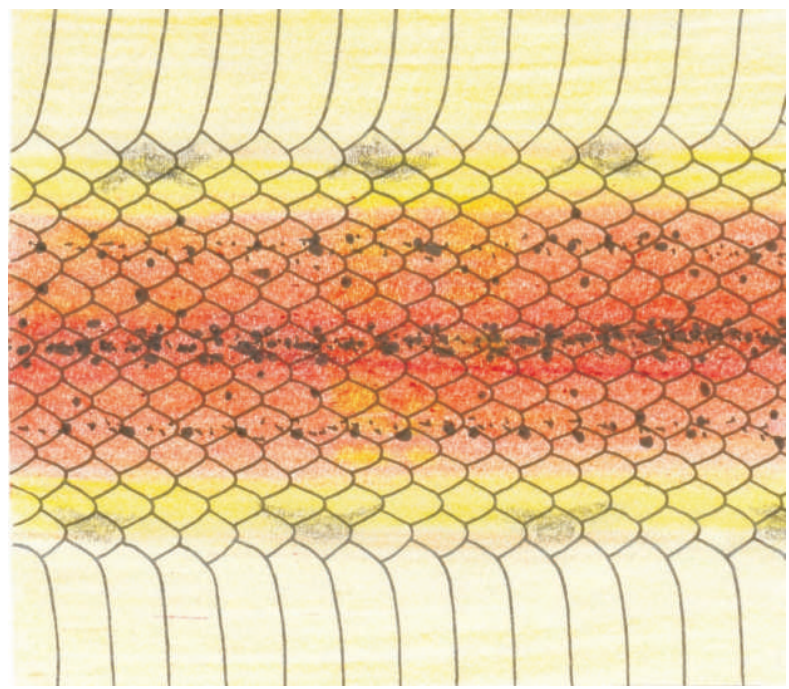

Fig. 1. Padrão de cor de Phalotris tricolor na região mediana do tronco (T. Lema del., com base em diversos exemplares).

cabeça e cauda desidratadas permitindo a observação do padrão de coloração, mas não a contagem de VE e SC; medidas aproximadas: COCA 27, COTR 886, COCU 57, COTO 970; relações $(\mathrm{R})$ entre elas: $\mathrm{R}_{1} 17 ; \mathrm{R}_{2} 0,059 ; \mathrm{R}_{3}$ 0,028 ; medidas de comprimento de placas cefálicas: SIN 1,0; PF 3,5; FR 6,0; SO 3,0; PA 12,0; MA 7,0/7,0 (E); diâmetro do olho para a DBO 1:3,5; distância da PA a DPF, 10. Folidose observada: PVC maior que a SIN; IN triangulares; PF muito maiores que as IN; FR pentagonal; SO pequena, quase isodiamétrica; PA longas e estreitas; PR 1/1, esquerda mais longa que a direita, PR direita isolada da NA pela PF; esquerda em forma triangular e apenas tocando a NA por um ponto; PS 2/2, a superior direita é maior que a inferior a ela sendo semelhantes entre si à esquerda; SL 6/6, segunda e terceira formam a margem orbital; TT $1+1 / 1+2$; TA muito longa, mais longa que TP, a direita TP é dividida superiormente, formando pequena placa retangular alongada; OC 2/2, grandes, superiores à direita com dois ápices (provável fusão de placas). Coloração da cabeça com o capuz preto descorado para castanho, apresentando manchas castanho-claras no focinho (PF, NA, RO); esse capuz atinge as três primeiras SL; IN pretas com margens claras; NA pretas centralmente; PF pretas anteriormente e posteriormente claras; anel nucal preto com margem reta encurvando posteriormente na última SL; anel nucal branco 4 DO vertebrais longo; anel cervical preto 9 DO vertebrais de comprimento e com saliência mediana na margem anterior do comprimento de 3 DO vertebrais; margem posterior irregular com denso pontuado preto que enfraquece posteriormente; o colar atinge os lados das VE decrescentemente posteriormente. Cor do focinho e SL similar à cor dorsal, mas um pouco mais escura que no dorso. Com raros pontos pretos pequenos espalhados dorsalmente tendendo a formar estrias na linha vertebral, anteriormente, e há algumas manchas pretas laterais distanciadas entre si na segunda fila de DO; os pontos pretos diminuem no meio do corpo e seu número aumenta no terço posterior, principalmente nos lados da cauda onde formam estrias paraventrais e paravertebrais. TE, levemente sombreada de castanho.

Comparação com a descrição original. Diferenças encontradas podem ser devidas ao estado do exemplar como, nas medidas, os comprimentos da cabeça, tronco, cauda e total que foram apresentados por DuMÉRIL et al. (1854) como 23, 861, 54 e 938 contra 27, 886, 57 e 970, mas mantendo-se a proporção caudal $\left(\mathrm{R}_{1}=17\right)$. DuMÉRIL et al. (1854) registraram que as NA contatam as PR, mas não informaram que, à direita, está fortemente isolada pela $\mathrm{PF}$ e que o contato na esquerda é apenas pontual (quase isolada). Afirmaram que as NA são grandes, sem compará-las. O mesmo quanto aos colares nuco-cervicais ("large", "enorme", respectivamente). A afirmativa de que há 2 PS, podendo haver fusão das mesmas, evidencia que viram mais de um exemplar. Ao mencionarem $3 \mathrm{TT}$ e que a "temporale médiane" ficava sobre a sexta SL, estavam confundindo a TP com a OC o que fica evidente quando disseram que a "TP" é semelhante a uma DO; não informaram que essa TP (mediana deles) estava dividida longitudinalmente (anomalia rara) e, portanto, há duas TP; da mesma forma há 2 OC (TP deles). Registraram que as VE variam de 212 a 216 , evidenciando novamente a existência de mais de um síntipo. Não indicaram o número

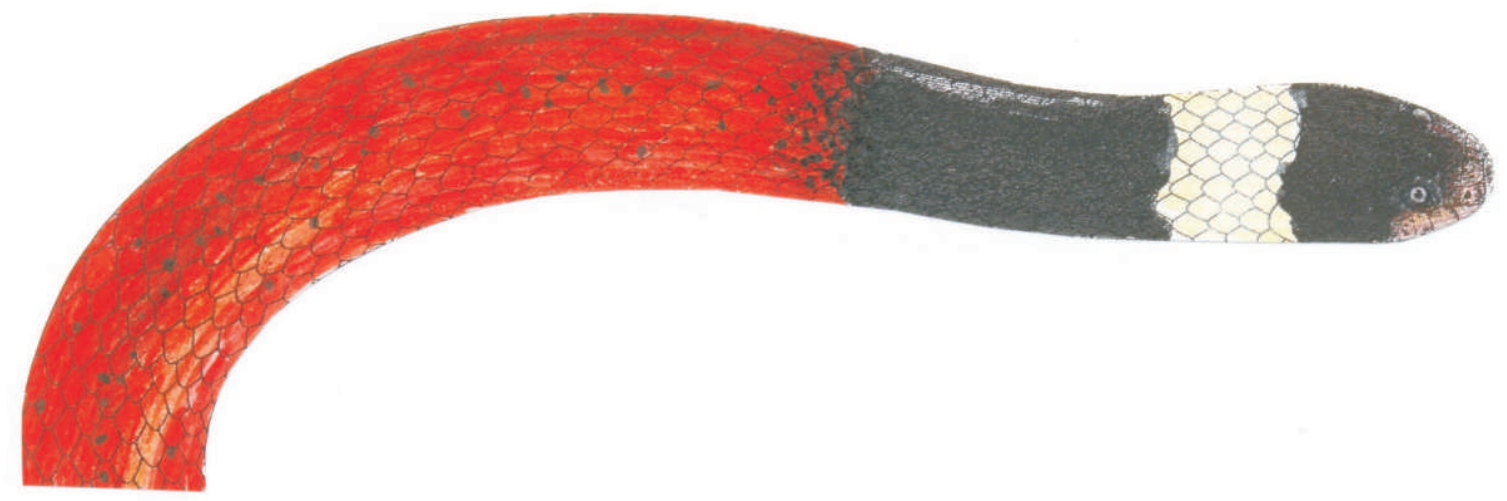

Fig. 2. Holótipo de Phalotris tricolor segundo JAN \& Sordeli (1865) (Cor com base em outros exemplares). 


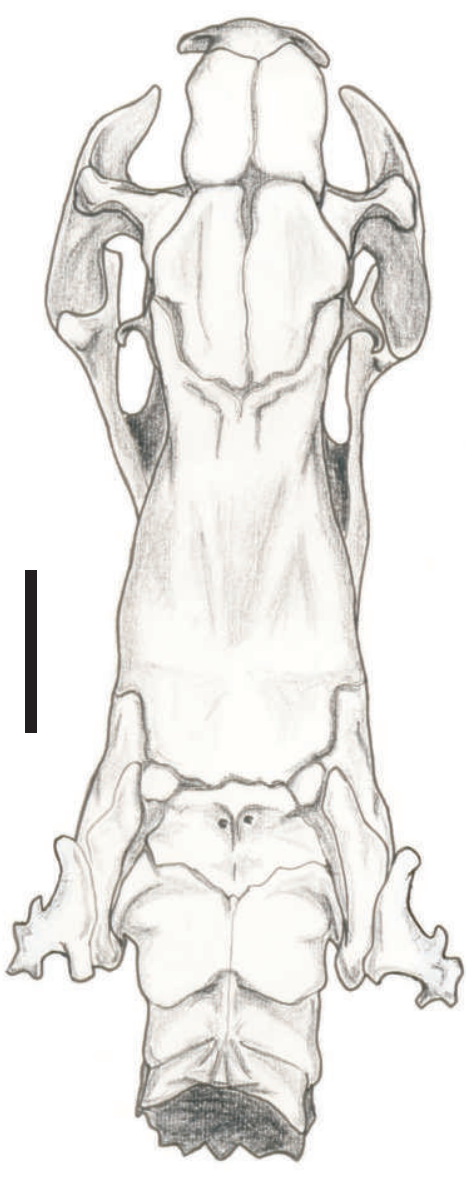

3

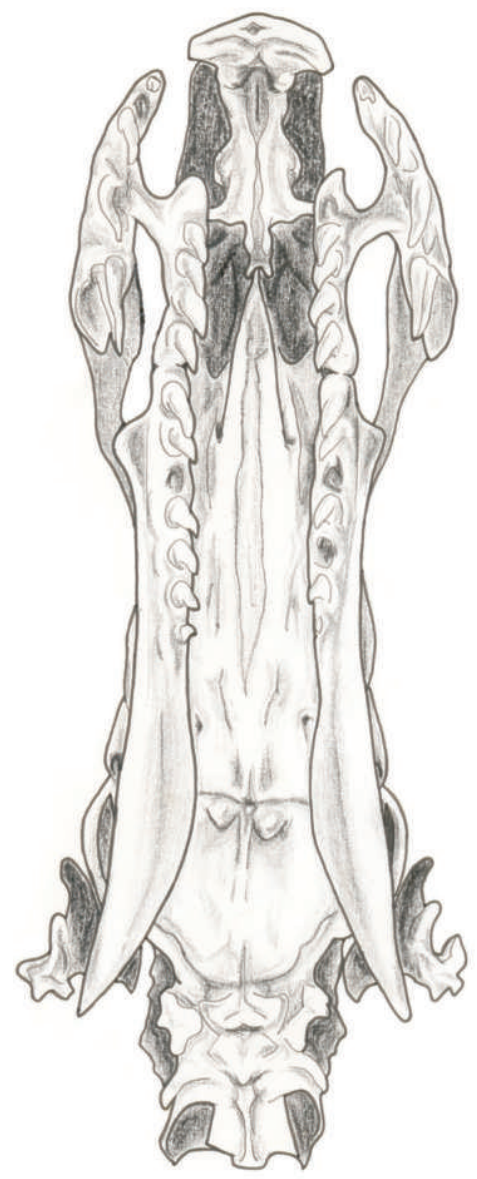

4

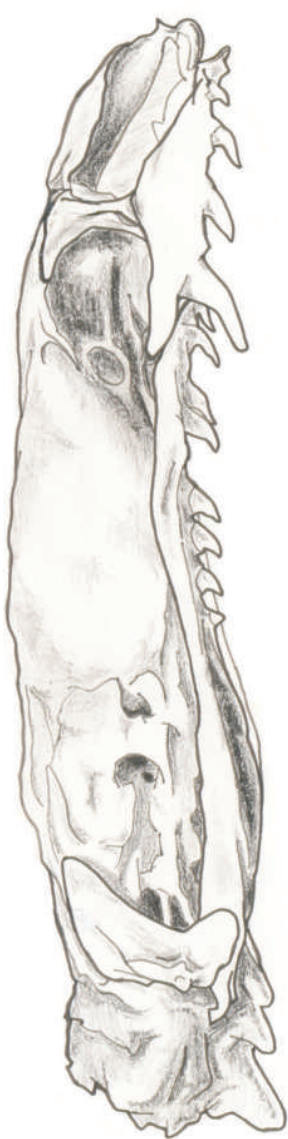

5

Figs. 3-5. Crânio de Phalotris tricolor (MHNP 5158): 3, dorsal; 4, palatal; 5, lateral (E. M. Lucchesi del.). Escala 2mm.

de SC. Descreveram a cor da ponta da cauda como branca para diferenciar de exemplares de Apostolepis que, naquela época, estavam no mesmo gênero. Ao descreverem a cabeça como preta, não mencionaram que o focinho é claro, mas que as primeiras SL e IL e região mental são branco-amareladas manchadas de cinza (o que vimos nas RO, NA, IN, parte do PF e OC) e que as IN e NA têm mancha preta central cada.

Caracteres complementares e variação. Corpo grosso e reforçado, da cabeça à cauda. Cabeça arredondada, mais alongada no macho jovem, mais larga e curta na fêmea; mais larga anteriormente (região ocular) e mais larga que o pescoço em vista dorsal, mais baixa vista de perfil, formando papo na região gular; área supracefálica menor que a face inferior da cabeça em vista dorsal, vendo-se as SL e TT; PA formam ângulo reentrante entre si. Focinho afilado, com ponta arredondada, levemente projetada sobre a mandíbula (só a RO), um pouco mais largo na fêmea. Olhos muito pequenos, com diâmetro menor que a metade da DBO e metade menor que a distância à narina; reentrantes, voltados para diante permitindo visão frontal ao animal; órbita algo ovalada e inclinada para frente; íris preta e pupila circular ou oval vertical, conforme a luminosidade na hora da morte. Narinas pequenas, ovóides, estreitas e obliquadas como as órbitas, sobre a metade anterior da NA. Tubérculos sensoriais arredondados e muito pequenos nas PF, sendo maiores nas pericloacais. Pescoço grosso e distinto da cabeça, muito mais alto e pouco mais estreito. Tronco subcilíndrico, pouco deprimido na zona vertebral com seção transversal subquadrada. Região cloacal saliente (VE e CL). Cauda curta e grossa, ponta cônica na fêmea e arredondada, com leve aresta, no macho.

Medidas e proporções: adultos, 300 a 970 de COTO. Fêmeas $(n=9)$ maiores que machos $(n=4)$. O menor exemplar da espécie, jovem, mede 281 (GIRAUDO, 2001). COCA representa 2,4-3,6\% do COTO, sendo 2,5-3,6\% nas fêmeas e 2,7-3,0 \% nos machos. COCU é quase 17 vezes do COTO, representando 5-10,5\% do total sendo 5-7\% nas fêmeas e 10-10,5\% nos machos. Os colares cromáticos variam um pouco nos sexos. De um modo geral, os machos apresentam porte menor que as fêmeas, mas, a rigor, o dimorfismo sexual praticamente não existe.

Folidose: RO pequena, mais larga que alta, variando de arredondada a pontuda no adulto, levemente projetada sobre a mental, ficando reforçada no adulto; $\mathrm{PVC}$ variável conforme a idade, de justo a igual à SIN. IN trapezoidais, pequenas e estreitas, largura igual ou menor que a metade da largura das PF e tão longa quanto a FR. SIN inclinada ou não, reduzida a ausente (raramente tocando $\mathrm{PF}$, como 


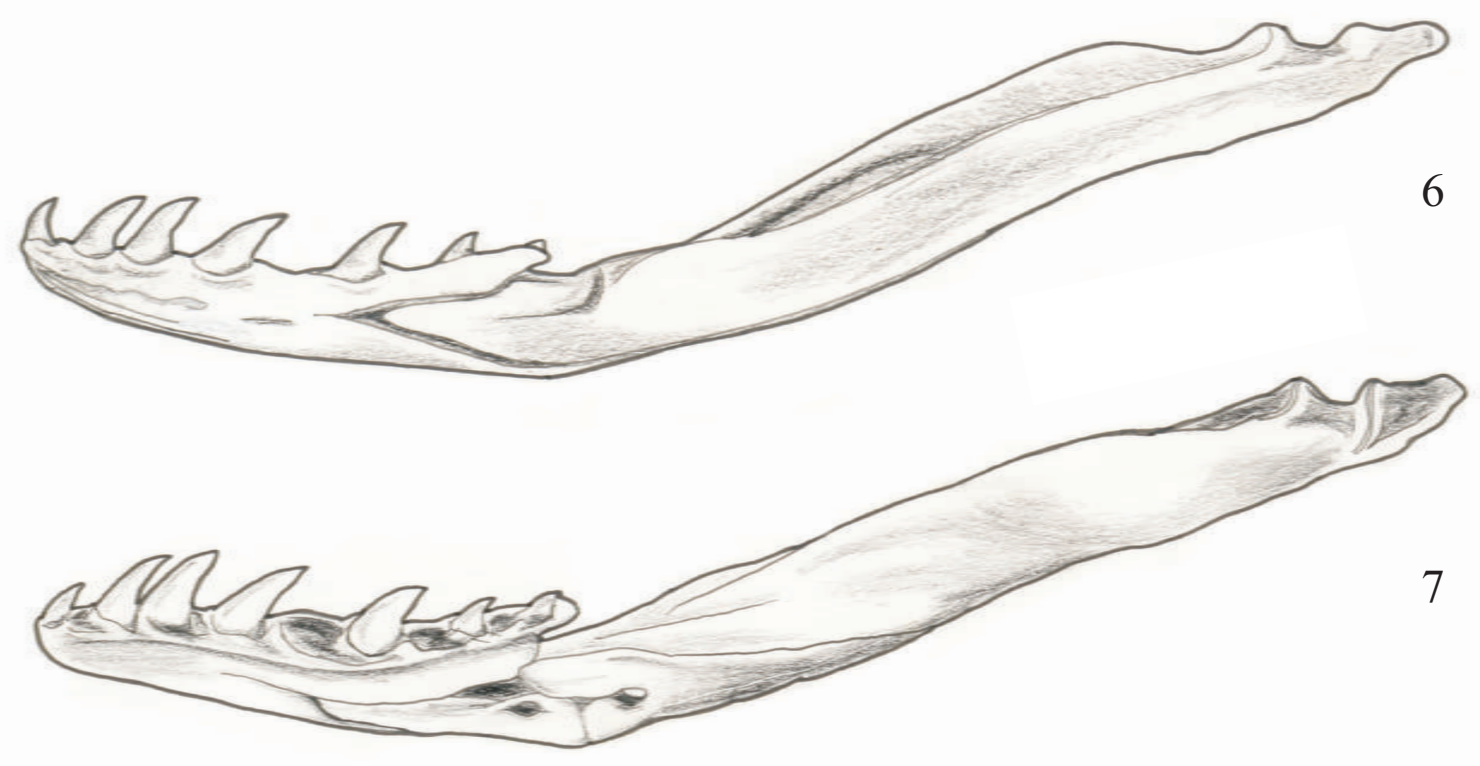

Figs. 6-7. Mandíbula de Phalotris tricolor (MHNP 5158): 6, externo; 7, interno (E. M. Lucchesi del.). Escala $2 \mathrm{~mm}$.

no FML 15). PF hexagonais, muito largas, podem tocar a segunda SL; comprimento igual à largura, com ângulo reentrante entre IN. FR pentagonal alongada, comprimento igual à DPF, maior que a metade da PA; mais longa que larga; ângulo posterior em triângulo isósceles; lados maiores paralelos ou pouco inclinados, retos ou côncavos; parte triangular com mesmo comprimento que a quadrangular; ápice inserto entre PA; comprimento $2 / 3 \mathrm{da}$ FR. SO retangulares, largos mas muito pequenos, tão longo quanto $\mathrm{PF}$, largura igual à $1 / 4$ da FR. PA longos e estreitos no jovem, alargado no adulto, mais largos anteriormente, com o dobro do comprimento da FR; mais longa que a DPF; sutura entre elas muito menor que o comprimento delas devido inserção da FR. NA alongadas, trapezoidais, mais altas anteriormente, geralmente contatam PR com sutura curta (pode estar dividida sob narina, sendo uma anomalia). PR pentagonais ou tetragonais, alongadas, com ângulo superior assimétrico entre elas e maior que cada PS (anomalia por divisão como no holótipo que apresenta 3/1). PS 2/2 (ou 1/1 por anomalia de fusão), superior maior que inferior e diferentes entre elas (variam de quadrangulares, pentagonais a losangulares), o ângulo da inferior insere-se entre a terceira e quarta SL. SL 6/6, segunda e terceira contatam órbita (por anomalia de fusão da quarta com quinta, como 6/5, holótipo, ou 5/6, ou de divisão, como 7/6), aumentando da frente para trás, sendo a primeira a menor e triangular e as outras quadrangulares; a quarta é estreita; quinta a mais alta e a sexta a mais longa. TT $1+1 / 1+1$, TA mais longa e estreita que TP, TP geralmente quadrangular podendo ser semelhante a uma DO; TP sempre menor que a sexta SL; pode ocorrer assimetria dos TT, ou mesmo fusões, resultando uma temporal muito longa (anomalias). OC $1 / 1$ ou $2 / 2$, quando ocorrem duas de cada lado, as superiores são quadrangulares e muito menores que a SL adjacente; as inferiores sempre semelhantes a DO, podendo ocorrer assimetrias entre PA e TP (superiormente) ou TP e SL (inferiormente). IL 7/7 ou 6/7 (ou 7/6) devido fusões; quatro primeiras contatam MA, quarta e quinta maiores, sendo a quinta a maior. ME relativamente grandes, mais alongadas nos jovens, triangulares e levemente salientes. MM 2/2, curtas e estreitas; MA largas e mais longas que MP, estas afiladas e divergentes com ápices isolados por GU. GU 6/6-8/8 séries laterais entre a última IL e primeira VE; GU medianas 4/4-7/7 podendo haver ímpares entre elas. PV 1-3. VE estreitas variando de 188-225 ( $\mathrm{x}=211,4)$, nos machos de 188-199 $(\mathrm{x}=191)$ e nas fêmeas $216-225(\mathrm{x}=219)$, podendo haver ázigos na região da centésima VE, ou VE menores anteriormente. CL 1/1, longa com margem arredondada, cerca do dobro do comprimento da última VE e mais estreita, esta última angulosa ou sinuosa. CL relativamente maior nas fêmeas. Pericloacais 4/4-5/5 (incluindo o par que forma a margem posterior da abertura cloacal, com ou sem placa intermediária). SC 21/21-32/32 ( $\mathrm{x}=35)$, nos machos 29/29-32/32 ( $=30$ ) e nas fêmeas $21 / 21-26 / 26$ (x $=23,6)$; mais longas que largas; as razões $\mathrm{R}_{4}$ 0,096-0,164, nos machos 0,154-0,164, nas fêmeas 0,096-0,120. SP em 8 filas anteriormente, 6 no meio e 4 em volta da TE (redução por fusão vertical de duas contíguas formando escamas semelhantes às $\mathrm{SC}$ e tendendo à forma ciclóide). TE deprimida e pontuda com leve aresta mediana nos machos, comprimento 1,5 da última SC. Anomalias: as fêmeas apresentam maior número de anomalias, e.g. VE divididas, fusão de TT e divisão em PA.

Coloração (figs. 8-11): capuz cefálico preto cobrindo quase toda a cabeça no adulto, estendendo-se para a face inferior na RM, com a RG geralmente manchada de preto. Focinho mais claro nos jovens, marmoreado de castanho-escuro ou claro na RO e IN, bem como na face 


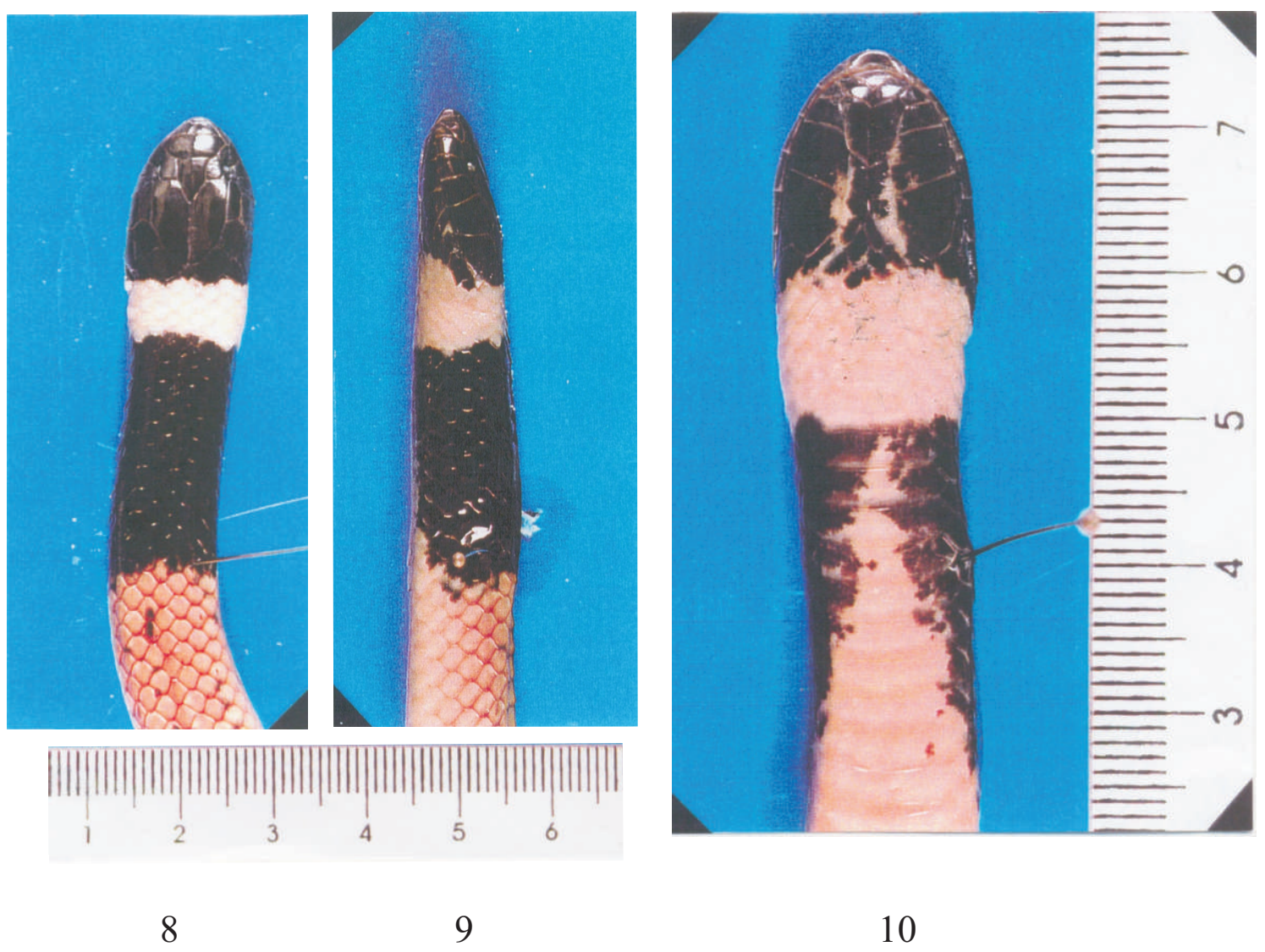

Figs. 8-10. Exemplar de Phalotris tricolor (MHNP 5161) de Boquerón, Paraguai: 8, dorsal; 9, lateral; 10, ventral. Nota-se que a mancha preta cervical quase forma colar completo (M. D. Bernardo fot.)

inferior da cabeça. Pode ocorrer pontuação clara na RO, primeiras SL e IL, SI e MA. RG geralmente creme, podendo ter pontos e/ou manchas pretas. Exemplares bem desenvolvidos podem apresentar a RG com manchas que se estendem para os lados dos primeiros VE sob o colar preto cervical. Anel preto nucal delimitando o capuz cefálico, com saliências laterais, mas geralmente sem ultrapassar o ângulo oral; pode atingir a RG, mas mesclado com pontos amarelados. Anel branco nucal atinge ápices dos PA e metade posterior da sexta SL, e a sexta e sétima IL; com comprimento de 3,5-6 DO vertebrais, geralmente 4,5. Anel preto cervical cobrindo 5-12 DO vertebrais, com freqüência maior de 8-10, sendo o mais longo de Elapomorphinae, comparável com Apostolepis breviceps Harvey, Gonzales \& Scrochi, 2001 e A. ambiniger (Peters, 1869), ambas do Chaco; margem anterior saliente 3 DO vertebrais longa, geralmente mais largo superiormente, estendendo-se para os lados das VE, quase fechando ventralmente nas primeiras VE e reduzindo-se para trás; a margem posterior do anel preto cervical é irregular e as escamas com diminutos pontos pretos que escurecem o dorso pós-anel, às vezes fusionam-se formando pequenas manchas; a pontuação ocorre em todo o dorso, diminuindo posteriormente, formando ou não três estrias irregulares pontuadas, com pontos espalhados. Há exemplares sem pontos ou escassamente pontuados, ou com a pontuação restrita à linha vertebral anteriormente e, nesses casos, surgindo nos lados da cauda. Dorsalmente, cor de fundo pardo-avermelhada, ficando amarelo-limão na zona paraventral que é geralmente imaculada, podendo haver exemplares com manchas escuras oblíquas e espaçadas, ao menos anteriormente no corpo nas duas primeiras filas de DO. Ventre amarelado da RG até as SC.

Hemipênis: curtos, invaginados atingem o sétimo par de SC representando $1 / 4$ do comprimento caudal. Bilobado, divisão a partir do último terço do órgão; lobos curtos e um pouco alargados. Sulcus spermaticus bifurcando-se um pouco antes da bifurcação do órgão; base lisa até o fim do primeiro terço. Todo espinhoso e cujos espinhos são pouco pontudos, delicados, dispostos em séries paralelas e reduzindo em tamanho para o ápice. Mio retractor magnus muito longos, inseridos próximo à extremidade da cauda.

Dentes: maxilas com 5-3 dentes $+1-2$ presas angulosas, partes basal e terminal com sulco iniciando estreito e profundo na frente da presa e torcendo para o lado externo, alargando-se ficando mais superficial distalmente. O último dente prediastemal muito pequeno, menos da metade da presa e menor que o diástema. Dentes do dentário 10-11, dentes palatinos 5, e dentes pterigoidianos 10 .

História Natural. A distribuição da espécie permitiu a CEI (1993) dizer que ela tem "grande versatilidade ecológica, desde ambientes áridos do Chaco até as províncias nitidamente mesófilas como Misiones". Praticamente pouco se sabe da alimentação e reprodução. Schouten (1931) registrou que A. de W. Bertoni, no Paraguai, observou ofiofagia em $P$. tricolor e anotou que 


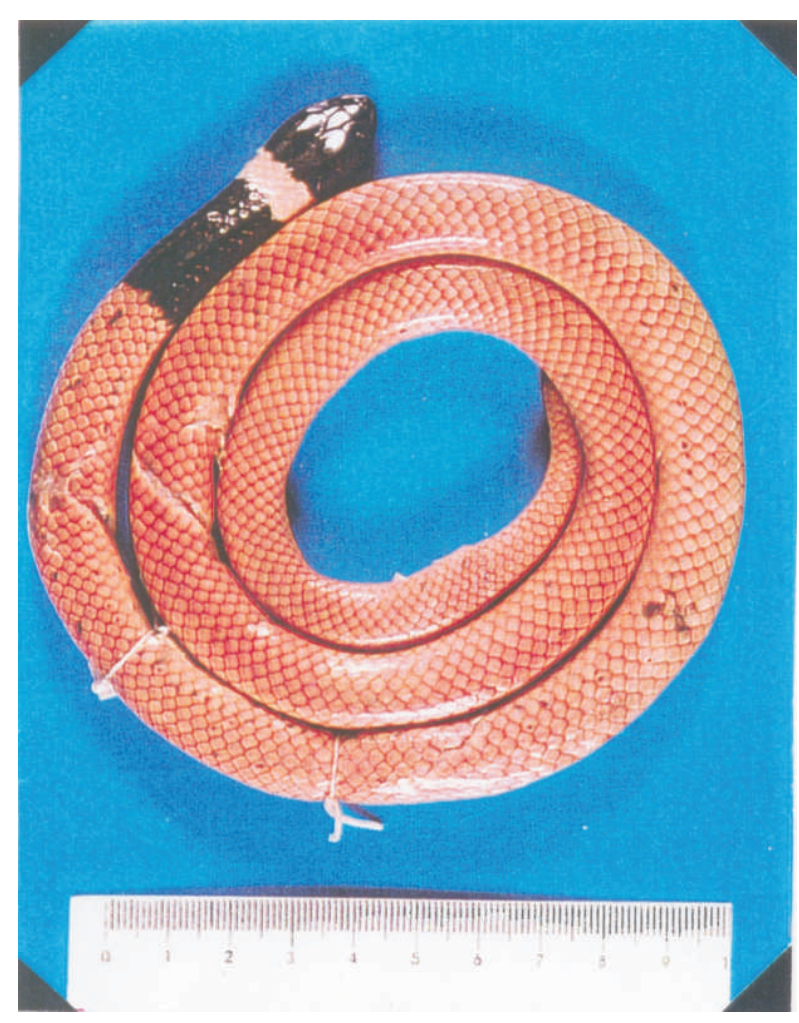

Fig. 11. Aspeto dorsal de exemplar de Phalotris tricolor (MHNP 5161) de Boquerón, Paraguai. Apesar de descorada ainda apresenta a cor dorsal pardo-avermelhada (M. D. Bernardo fot.)

o exemplar mordeu e engoliu uma Xenodon sp. Registrou, também, ter visto exemplar em cativeiro que, após longo período de jejum, comeu indivíduo de Sibynomorphus sp. e que vira outros espécimes em cativeiro comerem Amphibia. Ativa à noite (Leynaud \& Bucher, 1999), atividade notada quando o animal sai de suas galerias subterrâneas, habitat normal de Elapomorphinae.

Toxicidade. LEYNAUD \& BUCHER (1999) afirmaram que esta espécie provoca envenenamento com sua mordida, mas sem especificar a presa. Há alguns casos registrados com outros Elapomorphinae (LEMA, 1978; VALLs-Moraes \& Lema, 1997).

Distribuição geográfica (fig. 22). A distribuição da espécie abrange o Chaco boreal para o austral, Bolívia meridional, Paraguai e norte da Argentina, domínio morfoclimático Chaco. Para nordeste da Argentina ela atinge Misiones por dispersão para leste.

Material examinado. ARGENTINA, sem indicação (UNEC 176*, UNEC 315*, MACN 36085*); Catamarca: Belén, $27^{\circ} 39^{\prime}$ 'S $-67^{\circ} 01^{\prime} \mathrm{O}$ (FML 15, parátipo de $P$. punctatus); Chaco: Resistencia, $27^{\circ} 27^{\prime} \mathrm{S}-58^{\circ} 59^{\prime} \mathrm{O}$ (MSNG $\mathrm{s} / \mathrm{n}^{\circ}$, parátipo de $P$. punctatus); Córdoba: capital, $31^{\circ} 24^{\prime}$ S $-64^{\circ} 11^{\prime} \mathrm{O}$ (MCN 9053, MCN 9054, MCN 6443, parátipo de P. punctatus); Corrientes: Itati, Yacareí, $27^{\circ} 16^{\prime} S-58^{\circ} 14^{\prime} \mathrm{O}$ (UNEC $315^{*}$ ); Entre Ríos: Puerto Yeruá - 31 ${ }^{\circ} 32^{\prime}$ S $-58^{\circ} 02^{\prime}$ O (CENA 3735); Formosa: capital, $26^{\circ} 10^{\prime} \mathrm{S}-58^{\circ} 10^{\prime} \mathrm{O}$ (CENA 3310, parátipo de P. punctatus); Misiones: capital, $23^{\circ} / 27^{\circ}-53^{\circ} / 55^{\circ} \mathrm{O}$ (FML 710 , parátipo de $P$. punctatus); Salta: La Paz, $23^{\circ} 33^{\prime}$ 'S $-63^{\circ} 13^{\prime}$ O (UNEC 176*);

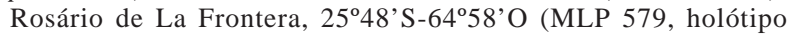
de $P$. punctatus, designado parátipo de $P$. tricolor); San Luís: Los Cerrillos, $34^{\circ} 23^{\prime}$ S $-66^{\circ} 24^{\prime} \mathrm{O}$ (CENA 3484); “Misiones Rurales", provavelmente Manantiales, $32^{\circ} 39^{\prime}$ 'S $-65^{\circ} 12^{\prime} \mathrm{O}$ (CENA 1445); Tucumán: Lara Tucamen, $26^{\circ} 49^{\prime}$ S $-65^{\circ} 12^{\prime} \mathrm{O}$ (CAS 14572). BOLÍVIA, Cordillera: Instituto Agronómico Nacional, próximo de Santa Cruz na Cordillera Oriental, $17^{\circ} / 18^{\circ} \mathrm{S}-63^{\circ} / 64^{\circ} \mathrm{O}$ (MHNP 2628); Misión San Francisco, próxima de Santa Cruz, 17 $47^{\prime}$ 'S $-63^{\circ} 12^{\prime} \mathrm{O}$ (MZUT s/n); Santa Cruz: San Bernardino, $14^{\circ} 50^{\prime}$ 'S-62 $62^{\circ} 08^{\prime} \mathrm{O}$ (ZSM 100/27); San José, $16^{\circ} 30^{\prime} \mathrm{S}-60^{\circ} 41^{\prime}$ 'O

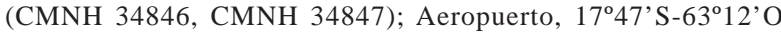
(USNM 132783), Santa Cruz de la Sierra (MNHN 520, holótipo de P. tricolor), Misión (IB 21655). PARAGUAI, sem indicação (ANSP 3307; NMW 13804, 21991; IB 19605); Areguá: região Central, 25ำ $18^{\prime}$ S $-57^{\circ} 25^{\prime}$ O (MHNP 2627); Asunción: capital, $25^{\circ} 17^{\prime} \mathrm{S}-57^{\circ} 37^{\prime} \mathrm{O}\left(\mathrm{MZUT} \mathrm{s} / \mathrm{n}^{\circ}\right)$; baía de Asunción, rio Paraná, $25^{\circ} 17^{\prime}$ 'S $-57^{\circ} 37^{\prime}$ O (IB 10109); Boquerón: $7 \mathrm{~km}$ sul de Filadélfia, $22^{\circ} 27^{\prime} \mathrm{S}-60^{\circ} 02^{\prime} \mathrm{O}$ (MHNP 5158); $28 \mathrm{~km}$ norte de Filadélfia, $22^{\circ} 04^{\prime} \mathrm{S}$ $59^{\circ} 59^{\prime} \mathrm{W}$ (MHNP 5161); $60 \mathrm{~km}$ SO de Filadélfia, km 462 da Ruta Transchaco, 22 $26^{\circ}$ 'S-60²6'S (MHNP 5159); Caaguazú: $5 \mathrm{~km}$ norte de Coronel Oviedo, $25^{\circ} 25^{\prime} \mathrm{S}-56^{\circ} 25^{\prime} \mathrm{O}$ (MHNP $\mathrm{s} / \mathrm{n}^{\circ}$ ).

Material adicional não examinado. BOLÍVIA, Santa Cruz:

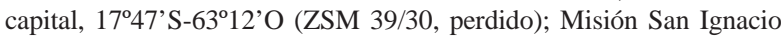
de Velasco, $16^{\circ} 22^{\prime}$ S-605'ㅇ (ZSM 184/1929, perdido)

\section{Phalotris matogrossensis sp. nov.}

(Figs. 12-14; 15-19; 20-22)

Elapomorphus tricolor; BOULENGER, 1896:239, 242; KOSLOWSKY, 1898:31; Peracca, 1904:10; Amaral, 1925:8; Werner, 1925:62; Hoge, 1955:301; Abalos et al. 1964:265, fig. 19; Peters \& OrejasMirANDA, 1970:105; LemA, 1979:851.

Elapomorphus (Phalotris) tricolor; LEMA, 1984:62, fig.17; CEI, 1993:549, figs.86, 88 .

Phalotris tricolor; Ferrarezzi, 1993:23; Aquino et al., 1996:365; Moura-Leite et al., 1996:217.

Localidade-tipo. Cuiabá, Mato Grosso, bairro Cophema, $15^{\circ} 37^{\prime} \mathrm{S} 5^{\circ} 05^{\prime} \mathrm{O}$. (fig.22).

Material-tipo. Holótipo. Adulto, macho. MCP 12801. Capturado em zona residencial por Christine Strüssmann, sem data. Mancha de vesícula biliar vazada. Esteve em cativeiro prolongado sem alimentação (figs.20, 21). Parátipos. IB 32338, IB 20621, IB 37435.

Diagnose. Difere de $P$. tricolor por apresentar o corpo mais delgado e longo, cabeça mais larga na altura dos olhos e focinho mais largo; capuz cefálico preto com focinho avermelhado escurecido de preto; face inferior cefálica branca imaculada, raramente com pontos pretos; colar branco muito longo, muito mais longo que o colar preto; colar preto curto, geralmente menos de 6 DO de comprimento; colar cervical nunca atinge VE; colar preto com margem posterior denteada sobre fundo vermelho coral, cor de fundo dorsal vermelha-coral imaculada, rosada no lado inferior, branca no ventre. $P$. tricolor tem o corpo mais reforçado, relativamente mais curto, cabeça da mesma largura que o pescoço, focinho com RO afilada no adulto, capuz totalmente preto no adulto, com focinho pardo-rosado manchado de preto no jovem, escurecido no adulto; face inferior da cabeça preta e pouco manchada de pardo; colar branco médio a curto, muito mais curto que o colar preto; colar preto cervical abrangendo até 12 DO de comprimento, atingindo as VE, podendo formar anel completo e com margem posterior irregular seguida de pontos e manchas pretas sobre fundo vermelho-pardo; cor de fundo dorsal pardo-avermelhada ou amarelada, com pontos pretos espalhados, formando ou não estrias irregulares e descontínuas, passando a amarelo-citrino no paraventre e ventre.

Difere de $P$. mertensi principalmente por não possuir as escamas dorsais com ápice preto e de $P$. cuyanus por não apresentar a coloração de base dorsal pardo-amarelada, semelhante a encontrada em $P$. tricolor. 
Descrição do holótipo. Cabeça curta, um pouco mais grossa que o pescoço, levemente alargada no nível anterior das PA, mais alta posteriormente, com focinho baixo e pouco projetado sobre a mandíbula, que tem margem anterior larga; pescoço muito mais alto que a cabeça, formando papo gular. Diâmetro ocular maior que a metade da DBO, íris preta e pupila elíptico-vertical larga. Narina na parte anterior da NA. Corpo longo com diâmetro igual em toda extensão. Cauda pequena, um pouco afilada, com ponta cônica e TE algo alongada e baixa apicalmente. Medidas e proporções: COCA 11,7; COTR 463,0; COCU 32,0; COTO 506,7. Medidas da cabeça: HA 5,3; ha 1,5; LA 7,1; la 3,2; diâmetro da órbita 1,1; DBO 1,4. Colares cromáticos: branco 6,8; preto 4,9. Diâmetros corpóreos: pescoço 4,9; tronco (meio do corpo) 6,2; antes da CL 5,1; base da cauda 3,3; metade da cauda 2,8; parte final 2,3; comprimento da TE 1,0; comprimento da última DO 0,9; comprimento da última SC 0,7 . Proporções: $R_{1}$ 15,$8 ; \mathrm{R}_{2} 0,063 ; \mathrm{R}_{3} 0,023$.

Folidose: RO mais larga que alta, $\mathrm{PVC}$ menor que SI, medindo 0,5 e 0,7 , respectivamente, sendo a SIN oblíqua. IN paralelogrâmica, mais larga que longa e com largura 1,7 e comprimento 0,9 , muito menores que PF. PF trapezoidais, grandes, mais longas que largas, com largura 3,5 e comprimento 2,2. SO pequenas, trapézio-retangulares, largura 1,2 e comprimento 2,1. FR pentagonal, com ápice arredondado e lados longitudinais assimétricos, sendo curvo à esquerda e anguloso à direita; parte angular $(2,3 \times 1,7)$ menor que a anterior retangular $(2,2 \times 5,5)$. NA longas, mais altas anteriormente, geralmente contata com PR. PR grandes, quadrangulares. PS estreitas, superior maior que inferior, inferior curva. SL 6/6, segunda e terceira na órbita; primeira triangular e menor de todas, segunda alongada em cima, terceira sob órbita, quarta sob PS inferior e sob TA, quinta maior de todas, pentagonal irregular, e sexta baixa. TA estreita e longa. TP alta e pouco longa. OC $1 / 1$, retangulares, contíguas aos PA e às TP. Anomalia nuco-vertebral: DO entre os ápices das PA é anômala, seguida de um par de DO iguais àquela, formando DO triangular à esquerda e DO irregulares na linha vertebral. ME triangular, pequena. IL 7/7, quatro primeiras contatam MA, quarta e quinta as MP; segunda é muito pequena assim como a sexta e a sétima. MA iguais às MP no comprimento, mas MA mais largas anteriormente e as MP afiladas e divergentes posteriormente. GU laterais $6 / 6$, medianas $3 / 3$, último par assimétrico. PV 2. VE 226. CL dividida, arredondada e estreita. SC 25/25. R4 = 0,111. DO em 15 filas, 8 na base da cauda, 6 na metade e 4 junto à TE; as reduções de DO na cauda são assimétricas e irregulares.

Coloração: capuz cefálico preto uniforme nas PA, $\mathrm{SO}$ e TA, com pequenas manchas vermelhas nas margens posteriores das $\mathrm{PF}$ e PR, e margens superiores da segunda à quinta SL, SO, FR, PS, TA e margens anteriores da OC. Focinho vermelho com manchas escuras irregulares na $\mathrm{RO}, \mathrm{IN}$ e NA. Face inferior cefálica com manchas escuras na margem oral do quarto IL, somente, sendo branco imaculado em quase toda RG e RM. Colar branco atinge ápices das PA estendendo-se por 4,5 DO vertebrais e 6 DO laterais e a RG; sua margem anterior com reentrância nas PA, e a posterior quase retilínea. Colar preto ocupa $1 / 2+2+2 / 3$ DO vertebrais e 3 DO laterais, atingindo a margem superior da primeira fila de DO; margem anterior com saliência de cada lado e a margem posterior com saliências laterais e levemente pontuada de preto nas escamas adjacentes. Cor de fundo dorsal vermelho-brilhante, clareando para rosa na quarta fila de DO e ficando branca na primeira; posteriormente, as duas primeiras filas são brancas; na cauda as duas primeiras filas têm os ápices vermelhos.

Caracteres gerais e variação. Morfologia: corpo delgado, muito longo, com diâmetro uniforme em toda sua extensão. Forma da cabeça (figs. 12-14) varia, sendo

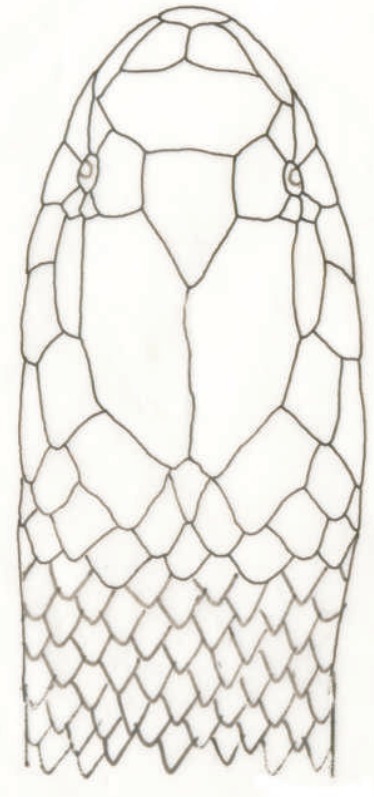

12

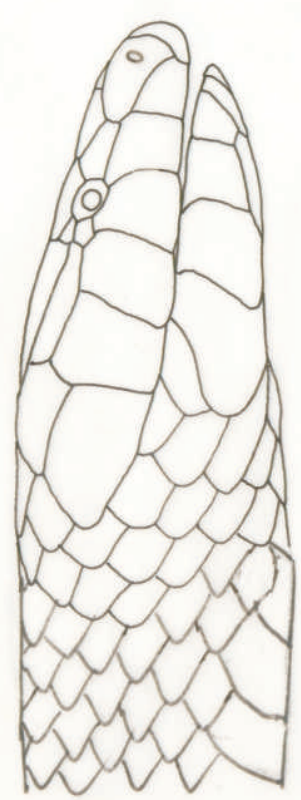

13

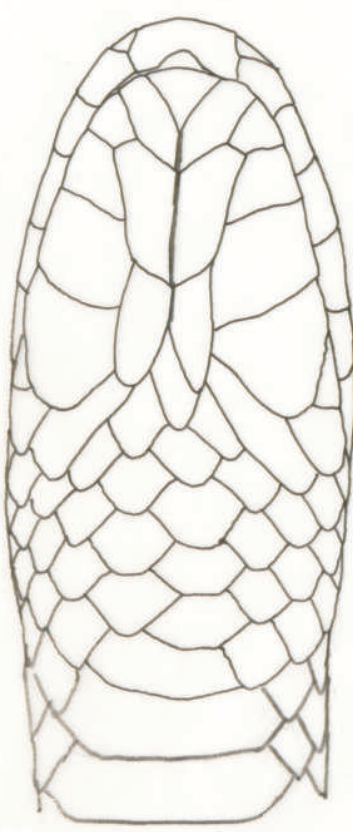

14

Figs. 12-14. Phalotris matogrossensis sp. nov.: morfologia e folidose cefálica (IB 21655): 12, dorsal; 13, lateral; 14, inferior (M. B. Martins del.). 

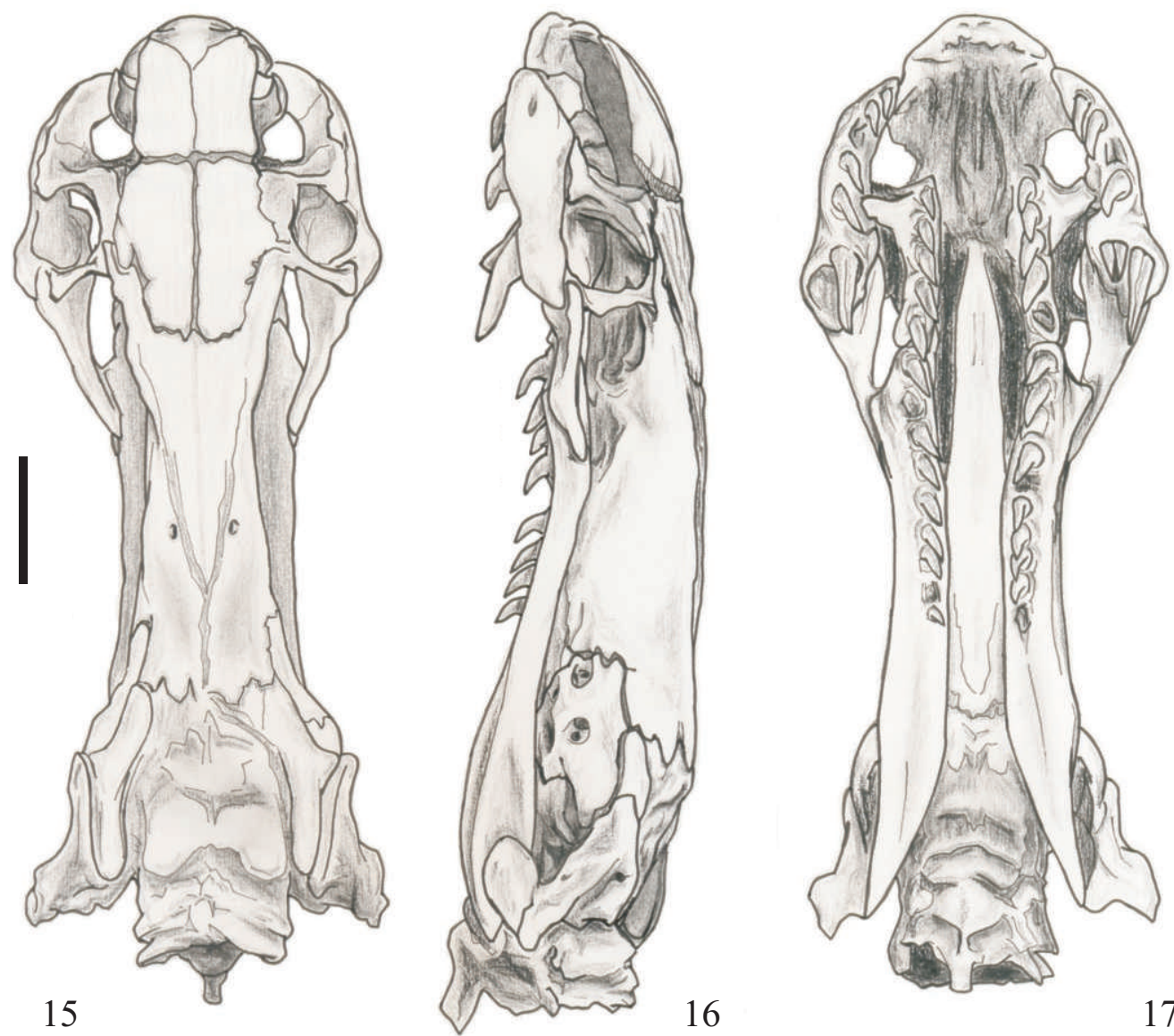

Figs. 15-17. Crânio de Phalotris matogrossensis sp. nov. (IB 21655): 15, dorsal; 16, lateral; 17, palatal. (C. H. Deiques del.). Escala $2 \mathrm{~mm}$.

geralmente mais larga em adulto macho, com leve alargamento no nível anterior das PA que é mais acentuado em fêmea adulta; pouco mais larga que pescoço no adulto, e quase igual no jovem; de um modo geral é curta, pouco mais curta na fêmea. PA fazem um ângulo diedro reentrante entre si nos exemplares de grande porte, como nas demais espécies do grupo tricolor. Focinho alto, levemente afilado, mas arredondado na ponta, projetado sobre mandíbula. Olhos pequenos, com diâmetro igual ou menor que a metade da $\mathrm{DBO}$ e pouco reentrantes; pupila varia de circular a elíptica vertical. Cauda curta e posteriormente afilada nas fêmeas, longa e pouco afilada nos machos; ponta cônica, TE pouco deprimida e com fraca aresta mediana dorsal. Medidas e proporções: porte geralmente pequeno, mas podendo atingir tamanho grande (e.g. USNM 32271, com 800 de COTO, sem procedência).

Folidose (figs. 12-14): RO tão larga quanto alta; PVC geralmente o dobro da SIN. SIN inclinada, curta, menos de $1 / 3$ ou metade do comprimento da PF, IN triangulares, mais largas que longas, mais longas que metade das SO. Comprimento das PF pouco menor que FR, maior que DPF. SO trapezoidal, comprimento igual ao dobro do diâmetro da órbita, tão longa quanto a PF. FR pentagonal, lados longitudinais um pouco oblíquos, parte apical angulosa com mesmo comprimento que a parte anterior quadrada; comprimento igual ao da PF + SIN, muito menor que DPF, e metade maior que sua largura. PA longas, paralelas, estreitas, de comprimento maior que quase o triplo de sua largura e maior que DPF. Anomalias: MCP 1747 apresenta $\mathrm{PA}$ retangulares com anomalia de fusão $\mathrm{PA}+\mathrm{OC}$ superior à direita, à esquerda a PA tem comprimento muito maior que DPF (anomalia rara). NA em triângulo-isósceles, com comprimento maior que o dobro da altura, mais longas que PR e geralmente contatando com aquela. PR triangulares, mais longas que o dobro da altura. PS pequenas, trapezoidais, superior maior e mais curta que inferior. SL 6/6 (quando há fusões, $5 / 6$ ou 6/5), segunda e terceira formam órbita e aumentam de altura ânteroposteriormente. TT 2/2, TA muito longa e estreita; TP grande, retangular, o dobro da altura da TA, mas o dobro mais curta que esta. Anomalia: TA vestigial, em forma de gota alongada horizontalmente sobre as quarta e quinta SL. OC $2 / 2$, levemente assimétricas, a superior esquerda maior que direita e as OC inferiores geralmente semelhantes a DO. DO nucal (entre ápices das PA) pode ser anômala e com divisões, ou muito longa seguida de 4/5 DO assimétricas. IL 7/7, quatro primeiras contatam MA; quarta e quinta maiores (raramente terceira e quarta maiores); sexta e sétima semelhantes a GU; primeiras maiores que segundas. ME, pequena; MM pequenas, estreitas, anteriores mais longas que posteriores, MP afiladas e 

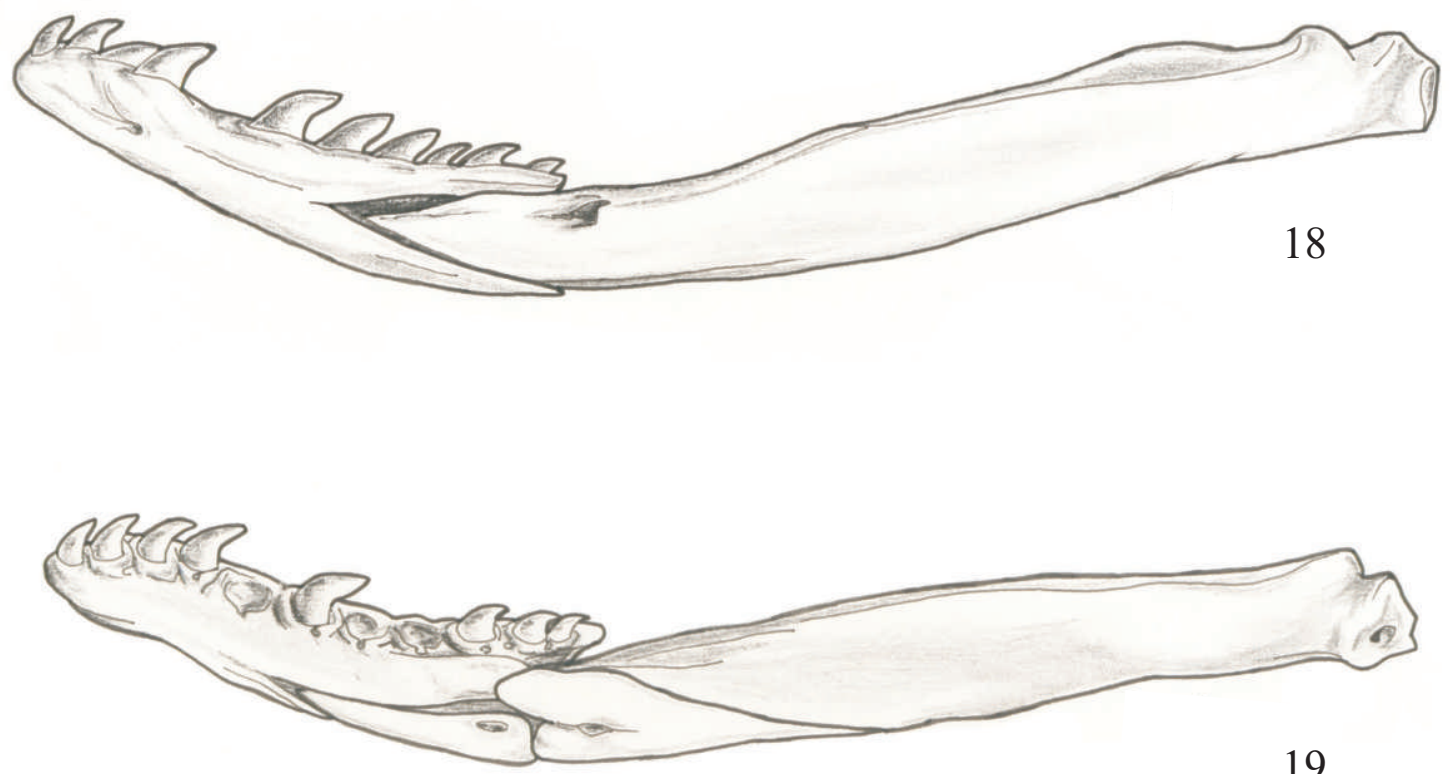

Figs. 18-19. Mandíbula de Phalotris matogrossensis sp. nov. (IB 21655): 18, externo; 19, interno. (C. H. Deiques del.). Escala 2mm.

divergentes. GU subiguais, laterais 5/5-6/6; medianas 3/3-4/ 4; podem ocorrer uma ou duas maiores na primeira fila, assimetricamente. PV 1-2. VE 185-240 ( $\mathrm{x}=205)$, nos machos $185-206(x=200)$ e nas fêmeas 206-240 $(x=212,4)$. SC 20-34 $(\mathrm{x}=26,6)$, nos machos 27-34 ( $\mathrm{x}=29)$ e nas fêmeas $20-26$ ( $\mathrm{x}=$ 22,9). $\mathrm{R}_{4}$ 0,099-0,161, machos 0,130-0,161 e fêmeas 0,0990,121 . CL semilunar nas fêmeas, mais longa que última $\mathrm{VE}$. TE cônica, comprimento é o dobro da última SC.

Coloração: capuz cefálico preto uniforme, focinho rosado-claro e com poucas manchas escuras irregulares nas SO, parte das FR, PF, IN, primeiras SL e PR; adulto com focinho escuro e fundo vermelho. RM imaculada, raramente ocorrendo manchas pequenas pretas na margem oral e ocasionalmente nas MM. RG branca imaculada. Colar nucal preto com margem reta, exceto saliência lateral que atinge a quinta e o ângulo superior da sexta SL. Colar branco estende-se dos ápices das PA e alongam-se por 4-5 DO vertebrais, sendo a margem anterior côncava (extensões do anel nucal preto) e a margem posterior retilínea. Colar preto cervical longo, 3$6 \mathrm{DO}$ vertebrais (normalmente 5); margens retas, um pouco onduladas anteriormente; margem posterior seguida de pontos pretos sobre a cor geral vermelha dorsal. Dorsalmente, cor de fundo vermelho-brilhante, rosada na região paraventral (segunda fila de DO) e branca na primeira fila de DO e na face ventral, da cabeça até à ponta da cauda. Alguns exemplares possuem vestígios de estrias pretas nos lados da cauda sob a forma de pontos pretos em série de cada lado (e.g. MCP 1747, 6/6 pontos, um em cada DO da primeira fila antes da TE). TE preta, geralmente uniforme, às vezes sombreada de cinza.

Hemipênis $(\mathrm{n}=3)$ : semelhante ao de $P$. tricolor, bilobado no terço distal e com ápice capitado. Espinhos muito pequenos e numerosos dispostos em filas paralelas e longitudinais. A diferença está no sulcus spermaticus que se bifurca proximalmente, abaixo da metade do órgão, enquanto que em $P$. tricolor dá-se no último terço, antes da bifurcação do órgão.

História Natural. Espécie própria do Cerrado, em sua porção ocidental, onde contata com o Chaco, região de tensão dos dois domínios. Habitante de áreas abertas (campos), vivendo dentro de galerias subterrâneas naturais (formadas, geralmente, pela morte de raízes ou por cursos d'água subterrâneos) ou escavadas por mamíferos e anfisbenas. Come larvas de insetos, oligoquetos e outros invertebrados que vivem nessas galerias, sendo presa de Micrurus frontalis (Duméril, Bibron \& Duméril, 1854) (VAnZOLINI, 1948).

Distribuição geográfica (fig. 22). Sudoeste do Brasil ao Paraguai oriental (fronteira); comum no Mato Grosso do Sul e Mato Grosso meridional. Encontrada desde Anápolis, oeste de Goiás, até Pinheiro Marcado, Carazinho, no Rio Grande do Sul, não havendo exemplares colecionados de Santa Catarina. Para GiRAudo (2001), não ocorre na Argentina, mas é provável sua ocorrência em Misiones cuja área estreita se insere entre o Brasil meridional e Paraguai, não havendo barreira significativa para sua distribuição, pois o rio Paraná nem sempre é barreira para répteis (LEMA, 1982), tendo sido vista na divisa entre o Brasil e o Paraguai.

Material examinado. Sem indicação (USNM 32271, IB 32838, IB 52763). BRASIL, Goiás: Anápolis, $16^{\circ} 19^{\prime} \mathrm{S}-48^{\circ} 55^{\prime} \mathrm{O}$ (IB 627); Mato Grosso: Cáceres, $16^{\circ} 03^{\prime} \mathrm{S}-5^{\circ} 42^{\circ} \mathrm{O}$ (IB 23971); Cuiabá, $15^{\circ} 37^{\prime}$ S- $56^{\circ} 05^{\prime} \mathrm{O}$ (MCP 12801); Mato Grosso do Sul: Água Clara (Santo Antônio), $20^{\circ} 27^{\prime}$ S-52 $2^{\circ} 52^{\prime} \mathrm{O}$ (IB 41058);

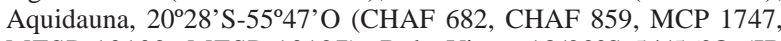
MZSP 10102, MZSP 10127); Bela Vista, $18 / 22^{\circ} \mathrm{S}-54 / 56^{\circ} \mathrm{O}$ (IB 32338); Bonito, $21^{\circ} 07^{\prime} \mathrm{S}-56^{\circ} 28^{\prime} \mathrm{O}$ (IB s/n ${ }^{\circ}$ ); Campo Grande, $20^{\circ} 27^{\prime}$ 'S $-54^{\circ} 37^{\prime} \mathrm{O}$ (CHAF 154, CHAF 156, CHAF 667, CHAF 678, MHNC 3081, IB 31868); Corumbá: margem do rio Taquari, $19^{\circ} 10^{\prime} \mathrm{S}-57^{\circ} 26^{\prime} \mathrm{O}$ (IB 31084); Miranda, $20^{\circ} 15^{\prime} \mathrm{S}-51^{\circ} 23^{\prime} \mathrm{O}$ (MLP $\mathrm{s} / \mathrm{n}^{\circ}$, perdido); Três Lagoas (Jupiá) $20^{\circ} 47^{\prime}-51^{\circ} 42^{\prime} \mathrm{O}$ (IB 20621 , IB 21655 (extraído crânio), IB 42640, IB 45114); Urucum, 

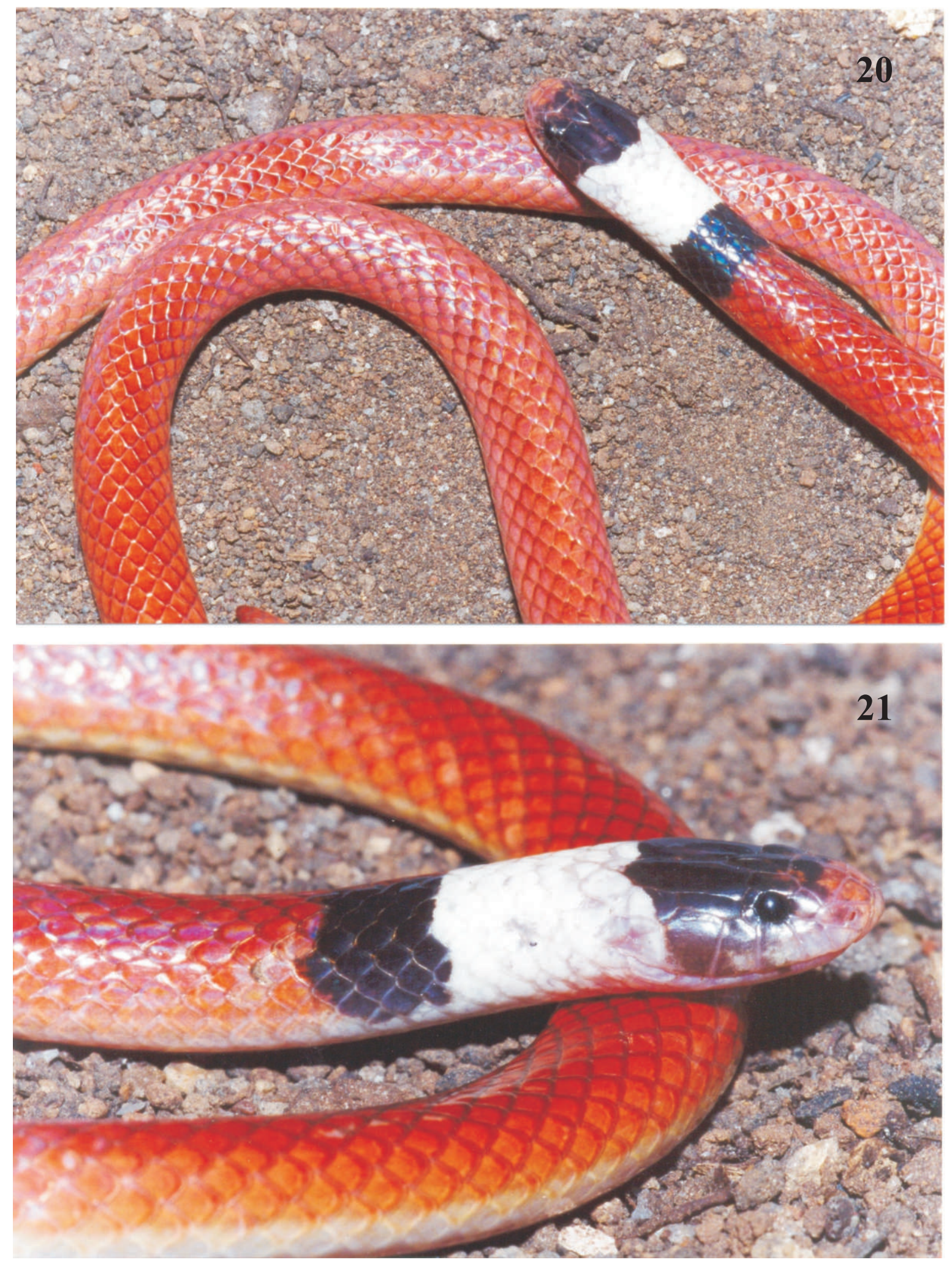

Fig. 20, 21. Phalotris matogrossensis sp. nov., holótipo (MCP 12801) de Cuiabá, Mato Grosso, Brasil. Fotografada ainda viva mostrando a cor dorsal vermelho-brilhante, o colar nucal branco longo avançando sobre a parte posterior cefálica (M. Di Bernardo fot.).

$19^{\circ} 09^{\prime} \mathrm{S}-57^{\circ} 37^{\prime} \mathrm{O}$ (MZUT s/nº, 2 exemplares, Peracca (1904)); Minas Gerais: Uberaba: Engenheiro Lisboa, $19^{\circ} 47^{\prime} \mathrm{S}-47^{\circ} 36^{\prime} \mathrm{O}$

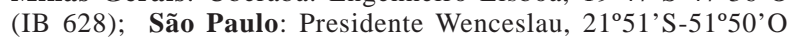
(IB 37435); Três Irmãos (Usina Hidrelétrica Três Irmãos), $20^{\circ} 44^{\prime}$ S $-51^{\circ} 22^{\prime}$ O (IB 53941). Paraná: Centenário do Sul, $22^{\circ} 48^{\prime}$ S $-51^{\circ} 37^{\prime} \mathrm{O}$ (MHNC 4876*). Rio Grande do Sul: Carazinho, Pinheiro Marcado (Seminário Menino Jesus), $28^{\circ} 17^{\prime} \mathrm{S}-$ $53^{\circ} 03^{\prime} \mathrm{O}$ (IPSP 005). PARAGUAI/BRASIL, entre os rios Paraná e Paraguai, rodovia Ciudad del Leste para Asunción, aproximadamente $25^{\circ} 28^{\prime} \mathrm{S}-56^{\circ} 20^{\prime} \mathrm{O}$ (ANSP 5816). 


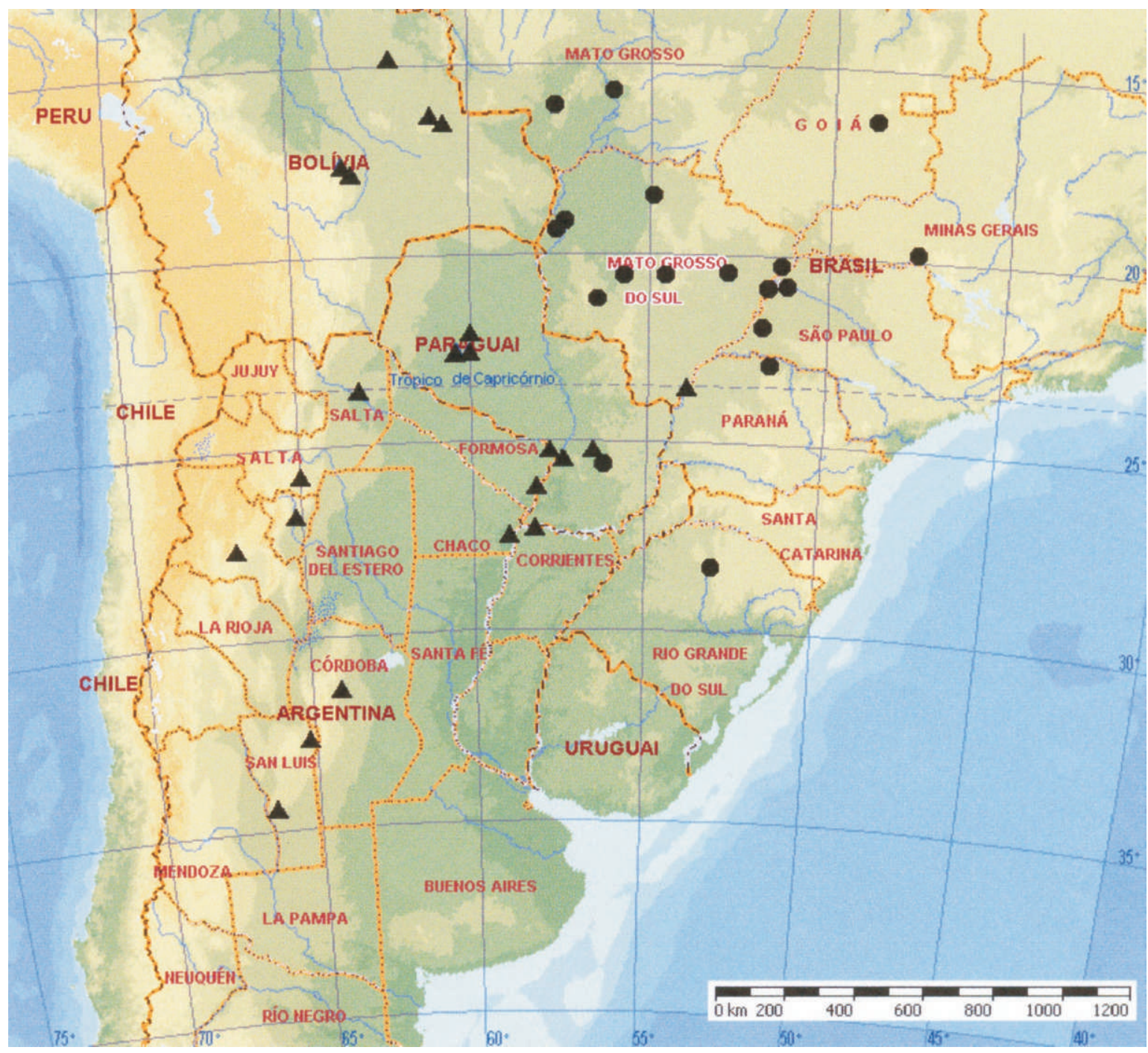

Fig. 22. Distribuição geográfica de Phalotris tricolor (triângulos) e Phalotris matogrossensis sp. nov. (círculos).

Osteologia craniana. Phalotris tricolor: exemplares MHNP 2628 e 5161, adultos, ambos de Boquerón, Paraguai (figs. 3-7); MCN 9053 e 9054, adultos, ambos de Córdoba, Argentina.

Crânio (figs. 3-5). Aspecto tubular em vista dorsal, com o pterigóide, ectopterigóide e maxilar visíveis. Leve acinturamento após a sutura do frontal com o parietal. Lateralmente, pequena elevação na sutura do parietal com o supraoccipital. Medidas: comprimento 16,5, largura 8,1 . Premaxilar com os processos palatais curtos, não atingindo o vômer e margem anterior elevada. Nasais alongados, com superfície dorsal retangular dividida anteriormente com entalhe em "V"; laterais lisas anteriormente em M e com processo látero-nasal; sutura posterior lisa e levemente arredondada na região láteroposterior; medianamente mais estreitos que anterior e posteriormente; articulação com premaxilar com sutura em "V". Comprimento 3,7, largura 2,8. Frontais hexagonais com superfície dorsal lisa, ântero-lateralmente retos na sutura com o nasal; asa ântero-lateral. Sutura com o parietal sinuosa e, lateralmente, o prefrontal atinge até quase a metade do osso. Pequeno forame mediano presente. Comprimento 3,5, largura 4,2. Parietais estreitos, muito longos, com aspecto tubular à cavidade craniana, com duas projeções laterais anteriores que atingem quase a porção mediana do frontal que medem, cada uma, 1,9; superfície lateral bulbosa mediano-posteriormente. Superfície dorsal lisa, apresentando duas cristas laterais mais evidentes a partir de um terço do osso; cristas unidas na última parte do osso, ficando uma crista saliente de altura decrescente posteriormente; margem posterior, na altura do encontro das duas cristas, com a projeção lateral formando ângulo reto e, posteriormente, duas projeções arredondadas, sendo a mediana a maior. Articula-se com o supraoccipital por sutura transversal. Comprimento 4,3, largura 2,1. Prefrontal com a parte superior mais larga que a inferior, levemente arqueado para a face externa. Forâme lacrimal localizado ventro-lateralmente, próximo à inserção do maxilar. Maxilar levemente arqueado, direcionado para a face interna. Dentes em $5+2$ a $3+1$, presas angulosas maiores que os dentes prediastemais e sulco fronto-lateral; dentes prediastemais menores que 
presas, aumentando gradativamente posteriormente (opistomegadonte). Um forâme na altura do terceiro dente. Palatinos alongados possuindo, anteriormente, apófise voltada para a face externa. Apresenta $5 / 5$ dentes. Pterigóideos longos; após os $3 / 4$ do osso há um alongamento que afina posteriormente até a margem posterior. $\mathrm{Na}$ altura do segundo dente, uma pequena apófise menor que a dos palatinos, voltada para a face externa e com um sulco que acompanha lateralmente os dentes. Apresenta 10 dentes à direita e 9 à esquerda. Ectopterigóide delgado possuindo duas apófises, a interna delgada e conspícua e a externa robusta e menor que a interna. Quadrado de aspecto triangular, disposto obliquamente com extremidade ântero-superior mais larga que a inferior. Superfície externa polida, sem processo. Comprimento 2,7, largura 2,5. Supraoccipital fusionado com o exoccipital formando figura em "V", com duas apófises ântero-laterais em direção ao parietal na margem anterior. Medianamente, há três cristas, duas laterais e uma mediana; margem posterior irregular. Exoccipital liso com leve sutura mediana e apófises arredondadas posteriores; apresenta fusão com proótico sem participar do processo em cima da fenestra ovalis, ou seja, ausência do processo paroccipital. Basioccipital com curto processo basioccipital na inserção do mio retractor capitis anterior, conduzido posteriormente ao centro do osso com uma crista curta transversal que se estende para a parte lateral do processo; sua posição no crânio é anterior. Supratemporal ultrapassa cerca de metade da caixa craniana, estendendo-se anteriormente até a sutura proótico-parietal atingindo o parietal. Complexo parabasisfenóide com estreito processo parasfenóide e esfenóide sem crista posterior para inserção do mio retractor pterygoidei e do mio protractor pterygoidei. Mandíbula (figs. 6-7). Dentário portando 11 dentes cada; dentes curvados, maiores do terceiro ao sétimo (mesomegadonte). Forâme mental na altura do quarto dente e forâme milo-hióideo posterior na altura do $11^{\circ}$ dente. Canal de Meckel mais evidente na altura do nono dente. Angular triangular afinando próximo ao final do dentário até a parte posterior. Esplenial em forma de dente com forâme milo-hióideo anterior, abaixo do canal de Meckel. Composto alongado cuja fossa mandibular corresponde cerca de metade do osso.

Comparação entre os crânios de $P$. tricolor e $P$. matogrossensis sp. nov. (figs. 15-19). Crânio do IB 21655 , adulto, de Jupiá, Três Lagoas, Mato Grosso, Brasil. Diferenças: (a) processo parabasisfenóide fortemente afilado anteriormente; (b) processo paroccipital em crista alongada abaixo da fenestra ovalis; parietal com crista dorso-lateral dirigida para a cauda, formando figura em cálice aberto para a região anterior do crânio, ocorrendo a união medianamente o que diferencia de $P$. tricolor em que a crista une-se posteriormente; (c) parietal com crista dorso-lateral muito alta, formando pequena elevação no parietal, sendo reduzida na altura em $P$. tricolor; (d) região ântero-mediana dos nasais forma processo agudo que se bifurca no ponto de articulação com o processo ascendente do premaxilar com concavidade anterior e que em $P$. tricolor os nasais são separados anteriormente por entalhe em "V".
Chave para identificação das espécies de Phalotris do grupo tricolor

1. Colar preto estreito (3-3,5 DO). Focinho vermelho geralmente manchado de preto. DO com ápice preto. Cor dorsal de fundo vermelha P. mertensi

Colar preto longo, com mais de 4 DO. Focinho vermelho, castanho, creme, preto uniforme ou manchado de preto. DO sem ápice preto. Cor dorsal de fundo vermelha, avermelhada ou pardo-amarelada

2

2(1). Colar preto com 6 DO em média. Colar branco muito mais longo que o preto (mais de 6 DO). Cor dorsal de fundo vermelho-brilhante. Focinho vermelho. RM e RG imaculadas P. matogrossensis sp. nov.

Colar preto com 6-12 DO. Colar branco muito mais curto que o preto. Cor dorsal de fundo pardoavermelhada ou pardo-amarelada. Focinho preto a castanho ou creme. RM e RG manchadas ou não ... 3

3(2). Cor dorsal de fundo castanho-avermelhada. Pontos pretos dorsais geralmente presentes. Focinho negro ou castanho manchado. RM e RG preta uniforme ou pouco manchada de creme. Colar preto com margem posterior irregular e escurecida atingindo face ventral .. P. tricolor

Cor dorsal de fundo pardo-amarelada, imaculada. Focinho creme com manchas. RM e RG claras ou pouco manchadas de preto. Colar preto com margem posterior sem manchas e escurecimento não atingindo face ventral P. cuyanus

Agradecimentos. Agradecemos aos seguintes colegas pelo envio de exemplares, dados e/ou figuras: Alejandro R. Giraudo (Universidad Nacional del Nordeste, Corrientes), Martha Motte (MHNP), Arlindo Figueiredo Beda (UFMS, Aquidauana), Adriana de Fonzo Abalos (Centro de Zoología Aplicada, Córdoba, Argentina), Marcos Carvalho e Christine Strüssmann (UFMT), Jorge Abalos (Córdoba, Argentina; in memoriam), Gilson de Oliveira (VIDEO-PUCRS), Maria de Fátima Domingos Furtado (IB), Marcos Di Bernardo (MCP). Eduardo Lucchesi e Carla Iara Pereira Rigotti (MCP), pela elaboração de desenhos. Nosso especial agradecimento ao curador da coleção do Museu de Paris, Ivan Ineich (MNHN), pelo empréstimo de exemplares-tipo.

\section{REFERÊNCIAS BIBLIOGRÁFICAS}

Abalos, J. W.; BÁEz, E. C. \& NAder, R. 1964. Serpentes de Santiago del Estero (Republica Argentina). Acta Zoologica Lilloana, 20:211-283.

Amaral, A. 1925. Contribuição II para o conhecimento dos ofídios do Brasil. Ophídios de Matto Grosso. In: Comissão de Linhas Telegráphicas e Estratégicas de Matto Grosso ao Amazonas. Historia Natural: Zoologia. São Paulo, Melhoramentos. 29p. (Publicação 85, Anexo 5).

Aquino, A. L.; Scott, N. J. \& Motte, M. 1996. Lista de anfibios y reptiles del Museo Nacional de Historia Natural del Paraguay (Marzo de 1980-Setiembre de 1995). In: MARTíneZ, O. R. ed. Colleciones de Flora y Fauna del Museo Nacional de Historia Natural del Paraguay. Asunción, Museo Nacional de Historia Natural del Paraguay. p.331-400.

Boettger, O. 1891. Bemerkungen über einige Reptilien des Naturhistorischen Museums d. N. G. N.: aus Peru, Brasilien, Cuba und Gross-Namaland. Jahresbericht der Naturhistorischen Gesellschaft zu Nürnberg, 1888. Abhandlungen der Naturhistorischen Gesellschaft zu Nürnberg, 8:91-93. 
Boulenger, G. A. 1896. Catalogue of the snakes in the collection of British Museum (Natural History). London, British Museum. v.3. i-iv $+727 \mathrm{p}$.

Cei, J. M. 1986. Reptiles del Centro, Centro-Oeste, y Sur de la Argentina. Herpetofauna de las zonas áridas y semiáridas. Torino, Museo Regionali de Scienze Naturali de Torino. 527p. (Monografia 4)

_- 1993. Reptiles del Noroeste, Nordeste y Este de la Argentina. Herpetofauna de las selvas subtropicales, Puna y Pampas. Torino, Museo Regionali de Scienze Naturali de Torino. 949p. (Monografia 14)

Cope, E. D. 1861. [Sem título]. Proceedings of Academy of Natural Sciences of Philadelphia (1861), 13:302; 524 (=302).

—_. 1862. Catalogues of the reptiles obtained during the expeditions of the Parana, Paraguay, Vermejo and Uruguay rivers, by Capt. Thos. J. Page, U. S. N., and of those procured by Lieut. N. Michler, U.S. Top. Engin., commander of the expedition conducting the survey of the Atrato river. Proceedings of Academy of Natural Sciences of Philadelphia, 1862:346-359.

—_. 1863. On part II of Prof. G. Jan's Prodromo della iconografia degli Ofidi [Review]. American Journal of Sciences \& Arts, Second Series, 35:455-458.

- 1885. Twelfh contribution to the Herpetology of Tropical America. VIII. RGS; H. Smith. Proceedings of American Philosophy Society of Washington (1884), 22(118):185-194.

Duméril, A. M. C.; Bibron, G. \& Duméril, A. 1854. Erpétologie générale ou Histoire Naturelle complète des Reptiles. Paris, Roret. v.7, 1936p.

Ferrarezzi, H. 1993. Nota sobre o gênero Phalotris com revisão do grupo nasutus e descrição de três novas espécies (Serpentes, Colubridae, Xenodontinae). Memórias do Instituto Butantan, 55(1):21-38.

Giraudo, A. R. 2001. La diversidad de serpientes de la selva Paranaense y del Chaco húmedo (Argentina) Taxonomía, biogeografia y conservación. Corrientes, LOLA. 281p. (Monografia)

Hoge, A. R. 1955. Eine neue Schlange der Gattung Elapomorphus aus Brasilien. Senckenbergiana Biologica, 36(5/6):301-304.

JAN, G. 1862. Enumerazione sistematica delle specie d'ofidi del gruppo Calamaridae. Archivio de Zoologia, Anatomia ed Fisiologia, 2(2): 1-76.

JAN, G. \& SoRdelli, F. 1865. Iconographie générale des ophidiens. Milano, éd. Des Auteurs. v.1, livr. 9-14.

Koslowsky, J. 1898. Ofidios de Matto-Grosso (Brasil). Revista del Museo de La Plata, 8:25-33

LEMA, T. 1978. Relato de um empeçonhamento por uma cobra não venenosa. Natureza em Revista, (4):62-63.

1979. Elapomorphus punctatus, nova espécie de Colubridae para a Argentina (Ophidia). Revista Brasileira de Biologia, 39(4):835-853

_- 1982. Fauna de serpentes da Província Pampeana e interrelações com as Províncias limítrofes. Memórias do Instituto Butantan, 46:173-182.

1984. Sobre o gênero Elapomorphus Wiegmann, 1843 (Serpentes, Colubridae, Elapomorphinae). Iheringia, Sér. Zoologia, (64):53-86.

Lema, T. \& Deioues, C. H. 1995. Estudo revisivo de Elapomorphus lepidus Reinhardt com a invalidação de E. wuchereri Günther,
E. accedens Jan e E. coronatus Sauvage mediante análise tipológica e a osteologia craniana (Serpentes, Colubridae, Xenodontinae, Elapomorphini). Biociências, 3(1):91-143.

Lema, T. \& Renner, M. F. 1998. O status de Apostolepis quinquelineata Boulenger, 1896, A. pymi Boulenger, 1903 e A. rondoni Amaral, 1925 (Serpentes, Colubridae, Elapomorphinae). Biociências, 6(1):99-121.

Leviton, A. E.; Gibbs JR., R. H. \& Danson, C. E. 1985. Standards in Herpetology and Ichthyology. Part I. Standards symbolic codes for institutional resources collections in Herpetology and Ichthyology. Copeia, 1985(3):802-832.

Leynaud, G. C. \& Bucher, E. H. 1999. La fauna de serpientes del Chaco Sudamericano: diversidad, distribución geográfica y estado de conservación. Córdoba, Academia Nacional de Ciencias. 46p. (Miscelanea 98)

Moura-Leite, J. C.; Morato, S. A. A. \& Bérnils, R. S. 1996. New records of reptiles from the state of Paraná, Brazil. Herpetological Review, 27(4):216-217.

Peracca, M. G. 1895. Viaggio del dott. Alfredo Borelli nella Republica Argentina e nel Paraguay. X. Rettili ed anfibi. Bolletino del Museo Regionale de Torino, 10(195):1-32. . 1904. Viaggio del Dr. A. Borelli nel Matto Grosso brasiliano e nel Paraguay, 1899. IX. Rettili ed anfibi. Bolletino del Museo Regionale de Torino, 19(460):1-15

Peters, J. A. \& Orejas-Miranda, B. 1970. Catalogue of the Neotropical Squamata, part 1, Snakes. Bulletin of the United States National Museum, (297):1-347.

Schouten, G. B. 1931. Contribuciones al conocimiento de la fauna herpetológica del Paraguay y de los paises limítrofes. Revista de la Sociedad Cientifica del Paraguay, 3(1):5-32.

SERIÉ, P. 1919. Enumeración de los ofídios de Tucumán. Primera Reunión Nacional de la Sociedade Argentina de Ciencias Naturales, Anales, (946):413-420.

1921. Catálogo de los ofidios argentinos. Anales de la Sociedad Cientifica Argentina, 92:145-175.

1936. Nueva enumeración sistemática de los ofidios argentinos. In: Obra del Cincuentenario del Inst. Museo de la Univ. La Plata. Buenos Aires, Museo Argentino de Ciencias Naturales Bernardino Rivadavia, v.2, p.33-68.

Strauch, A. 1885. Bemerkungen über die Schlangengattung Elapomorphus aus der Familie der Calamariden. Bullétin de l'Académie Impériale des Sciences de Saint Petersbourg, 29:541-590.

Valls-Moraes, F. \& Lema, T. 1997. Envenomation by Phalotri. trilineatus in Rio Grande do Sul State, Brazil: A case report. Journal of Venomous Animals and Toxins, 3(1):106 (On line)

VANZolini, P. E. 1948. Notas sobre ofídios e lagartos da Cachoeira de Emas, no município de Pirassununga, Estado de S. Paulo. Revista Brasileira de Biologia, 8(3):377-400.

WERNER, F. 1925. Neue oder wenig bekannte Schlangen aus dem Wiener Naturhistorischen Staatsmuseum (2.) Teil. Sitzungsbericht der Akademie der Wissenschaften zu Wien, Abteilung I, 134(1-10):45-66.

Williams, J. D. \& Francini, F. 1991. A checklist of the Argentine snakes. Bolletino del Museo Regionale de Scienze Naturali deTorino, 9(1):55-90.

Recebido em junho de 2004. Aceito em janeiro de 2005. ISSN 0073-4721

Artigo disponível em: www.scielo.br/isz 